\title{
The Arabidopsis SAC9 Enzyme defines a cortical population of early endosomes and restricts $\mathrm{PI}(4,5) \mathrm{P}_{2}$ to the Plasma Membrane
}

\author{
Mehdi Doumane $\dagger^{1}$, Alexis Lebecq $\dagger^{1}$, Aurélie Fangain ${ }^{1}$, Vincent Bayle ${ }^{1}$, Frédérique Rozier ${ }^{1}$, Maria del \\ Mar Marquès-Bueno ${ }^{1,3}$, Romain P. Boisseau ${ }^{2}$, Mathilde Laetitia Audrey Simon ${ }^{1}$, Laia Armengot ${ }^{1}$, \\ Yvon Jaillais $^{1 *}$, Marie-Cécile Caillaud ${ }^{1 *}$ \\ 1 Laboratoire Reproduction et Développement des Plantes, Université de Lyon, ENS de Lyon, CNRS, INRA, F-69342 Lyon, \\ France. \\ 2 Division of Biological Science, University of Montana, Missoula, MT 59812, USA. \\ ${ }^{3}$ Current address: Department of Molecular Genetics, Center for Research in Agricultural Genomics (CRAG), CSIC-IRTA- \\ UAB-UB, Campus UAB, Bellaterra (Cerdanyola del Vallès), 08193, Barcelona, Spain. \\ $\dagger$ The authors contributed equally to this work \\ *Corresponding authors: yvon.jaillais@ens-lyon.fr; marie-cecile.caillaud@ens-lyon.fr
}

Short title: SAC9 prevents the intracellular accumulation of $\mathrm{PI}(4,5) \mathrm{P}_{2}$ in plant cells.

One-sentence summary: SAC9 prevents the accumulation of $\mathrm{PI}(4,5) \mathrm{P}_{2}$ along the endocytic pathway in plants and thereby contributes to the clathrin mediated endocytosis process at the plasma membrane via its interaction with $\mathrm{SH} 3 \mathrm{P} 2$

Keywords: Arabidopsis, endocytosis, phosphoinositides, early endosome, plasma membrane 


\section{ABSTRACT 200 words}

Membranes lipids, and especially phosphoinositides, are differentially enriched within the eukaryotic endomembrane system. This generates a landmark code by modulating the properties of each membrane. Phosphatidylinositol 4,5-bisphosphate $\left[\mathrm{PI}(4,5) \mathrm{P}_{2}\right]$ specifically accumulates at the plasma membrane in yeast, animal and plant cells, where it regulates a wide range of cellular processes including endocytosis. However, the functional consequences of mispatterning $\mathrm{PI}(4,5) \mathrm{P}_{2}$ in plants are unknown. Here, we functionally characterized the phosphoinositide phosphatase SUPPRESSOR OF 7 ACTIN9 (SAC9) in Arabidopsis thaliana (Arabidopsis). We found that SAC9 depletion led to the 8 ectopic localization of $\mathrm{PI}(4,5) \mathrm{P}_{2}$ on cortical intracellular compartments, which depends on PI4P and $9 \mathrm{PI}(4,5) \mathrm{P}_{2}$ production at the plasma membrane. SAC9 localizes to a subpopulation of trans-Golgi 10 Network/early endosomes that are spatially restricted to a region close to the cell cortex and that are 11 coated with clathrin. Furthermore, it interacts and colocalizes with the endocytic component Src 12 Homology 3 Domain Protein 2 (SH3P2). In the absence of SAC9, SH3P2 localization is altered and the clathrin mediated endocytosis rate is significantly reduced. Thus, SAC9 is required to maintain efficient

14 endocytic uptake, highlighting the importance of restricting the $\mathrm{PI}(4,5) \mathrm{P}_{2}$ pool at the plasma membrane 15 for the proper regulation of endocytosis in plants. 
Phosphoinositides constitute a family of low abundant lipids differentially enriched in the membranes of eukaryotic cells (Platre and Jaillais 2016; Balla 2013; Noack and Jaillais 2020). These versatile lipids can be interconverted into one another. For example, Phosphatidylinositol 4,5biphosphate $\left[\mathrm{PI}(4,5) \mathrm{P}_{2}\right]$ is synthetized from Phosphatidylinositol 4-phosphate (PI4P) by PI4P-5 kinases, and is dephosphorylated into PI4P by PI(4,5) $\mathrm{P}_{2}$ 5-phosphatase (Noack and Jaillais 2017). Furthermore, $\mathrm{PI}(4,5) \mathrm{P}_{2}$ and PI4P are targeted by phospholipases $\mathrm{C}$ (PLC) into diacylglycerol and soluble phosphorylated inositol (Balla 2013). $\mathrm{PI}(4,5) \mathrm{P}_{2}$ strictly localizes at the plasma membrane in plants and animal cells (van Leeuwen et al. 2007; Carim et al. 2019; Del Signore et al. 2017; Simon et al. 2014; Ben El Kadhi et al. 2011) despite the plasma membrane being constantly turned-over by endocytosis and exocytosis. At the plasma membrane, $\mathrm{PI}(4,5) \mathrm{P}_{2}$ interacts with a variety of extrinsic membrane proteins such as endocytic protein adaptors (Zhang et al. 2015) and actin-regulatory proteins (Paez Valencia et al. 2016), which are recruited and/or activated by the binding to $\mathrm{PI}(4,5) \mathrm{P}_{2}$. Therefore, $\mathrm{PI}(4,5) \mathrm{P}_{2}$ subcellular patterning likely is critical to regulate the recruitment of proteins that act at the plasma membrane, and the cellular processes they mediate, including clathrin-mediated endocytosis.

Consistent with a critical role of $\mathrm{PI}(4,5) \mathrm{P}_{2}$ in the recruitment of the early clathrin-mediated endocytosis factors, a pip5k1 pip5k2 double mutant in Arabidopsis thaliana (Arabidopsis) lacking two ubiquitously expressed PI4P-5 kinases, has abnormal auxin distribution and defective endocytic trafficking of the transmembrane auxin efflux carriers PIN-FORMED 1 (PIN1) and PIN2 (Tejos et al. 2014; Ischebeck et al. 2013; Mei et al. 2012). Furthermore, the pip5k1 pip5k2 double mutant has an altered dynamic of CLATRHIN LIGHT CHAIN2 (CLC2), with the density of CLC2 foci at the plasma membrane being reduced in the mutant (Ischebeck et al. 2013). Overexpression of Arabidopsis PI4P-5 kinase 6 in tipgrowing pollen tubes induced massive aggregation of the plasma membrane in pollen tube tips due to excessive clathrin-dependent membrane invagination, supporting a role for $\mathrm{PI}(4,5) \mathrm{P}_{2}$ in promoting early stages of Clathrin-mediated endocytosis (Zhao et al. 2010). The inducible overexpression of a highly active human PI4P-5 kinase leads to an increase $\mathrm{PI}(4,5) \mathrm{P}_{2}$ production, very strong developmental phenotypes and heightened endocytic trafficking toward the vacuole (Gujas et al. 2017). In addition, we recently showed that inducible depletion of the $\mathrm{PI}(4,5) \mathrm{P}_{2}$ from the plasma membrane using the iDePP system leads to a decrease of the fraction of the clathrin adaptor protein AP2- $\mu$ and the Src Homology (SH3)-domain containing protein 2 (SH3P2) at the plasma membrane (Doumane et al. 2021). Furthermore, FM4-64 uptake experiment confirmed an impact of $\mathrm{PI}(4,5) \mathrm{P}_{2}$ depletion from the plasma membrane on bulk endocytic flow. endocytosis (He et al. 2017; Pirruccello et al. 2014). Many PI(4,5) $\mathrm{P}_{2}$ phosphatases belong to the 5- 
Phosphatase enzyme family, including OCRL and synaptojanins (Syn1/2) in animals, and synaptojaninlike proteins (Inp51p/Snj11p, Inp52p/Sj12p and Inp53p/Sj13p) in Saccharomyces cerevisiae. The Arabidopsis genome contains 15 genes encoding 5-phosphatases, but only a few are characterized. Mutation in the 5-phosphatases 9 leads to osmotic stress tolerance, with reduced reactive oxygen species production and $\mathrm{Ca}^{2+}$ influx (Golani et al. 2013). The 5-phosphatases 6/COTYLEDON VASCULAR PATTERN2 (CVP2) and 5-phosphatases 7/CVP2 LIKE 1 (CVL1) are specifically required for vascular differentiation (Rodriguez-Villalon et al. 2015; Carland and Nelson 2009; Carland and Nelson 2004). Finally,the 5-phosphatases 15/FRAGILE FIBER 3 (FRA3) is expressed in developing fibers and vascular cells, which is consistent with the defective fiber and vessel phenotypes seen in the loss-offunction fra3 mutant (Zhong et al. 2004).

Proteins containing SUPPRESSOR OF ACTIN (or Sac1-like) domains constitute another family of phosphoinositide phosphatases (Zhong and Ye 2003). In Arabidopsis, there are nine SAC proteins, forming three clades (Zhong and Ye 2003). The first clade is composed of SAC1, a PI(3,5) $\mathrm{P}_{2}$ 5phosphatase (Zhong et al. 2005), and its relatives SAC2 to 5, putative $\mathrm{PI}(3,5) \mathrm{P}_{2}$ 5-phosphatases (Novakova et al. 2014). The second clade corresponds to SAC7/RHD4 a PI4P 4-phosphatase (Thole et al. 2008) and its relatives SAC6 and SAC8 putative PI4P 4-phosphatases (Song et al. 2021). The third clade is composed of a single member, a plant-specific protein called SAC9. SAC9 has a unique structure, with a SAC phosphoinositide phosphatase domain at its N-terminus, immediately followed by a putative protein/protein interaction domain (WW domain), and a long C-terminal region of 1104 amino acids where no putative domains are predicted by sequence homology analysis (Figure 1A, (Zhong and Ye 2003). The sac9 mutants is dwarf and it constitutively accumulates anthocyanins and expresses genes from stress response pathways (Williams et al. 2005). Loss-of-function alleles of SAC9 display a three-fold increase in $\mathrm{PI}(4,5) \mathrm{P}_{2}$ content, together with a decrease of PI4P level, suggesting that it acts as a PI(4,5) $\mathrm{P}_{2}$ 5-phosphatase in planta (Williams et al. 2005).

In this study, we show that the phosphoinositide phosphatase activity of SAC9 is required for its function. Using in vivo confocal microscopy, we found that SAC9 localizes in a subpopulation of transGolgi network/early endosomes (TGN/EEs) spatially restricted to a region close to the cell cortex. Loss of SAC9 results into $\mathrm{PI}(4,5) \mathrm{P}_{2}$ mis-patterning at the subcellular level, leading to the accumulation of $\mathrm{PI}(4,5) \mathrm{P}_{2}$ in subcortical compartments associated with TGN/EEs. SAC9 interacts and colocalizes with the endocytic component SH3P2. In the absence of SAC9, and therefore when the patterning of the $\mathrm{PI}(4,5) \mathrm{P}_{2}$ is compromised, SH3P2 localization is affected and the CLC dynamics is significantly reduced. Thus, SAC9 is required to maintain efficient endocytic uptake, highlighting the importance of restricting the $\mathrm{PI}(4,5) \mathrm{P}_{2}$ pool to the plasma membrane for proper endocytosis in plants. 
The cysteine 459 in the catalytic domain of SAC9 is required for its function

86

We investigated the root phenotype in the already described mutant alleles of SAC9 (Vollmer et al. 2011; Williams et al. 2005). As previously described, sac9-1/ and sac9-3\% knock-out mutants are two times shorter compared to the Wild-type (WT) Col-0, at 12 days post-germination (dpg; Figure 1B and 1C). We also observed a three-time decrease in the lateral root density of $\operatorname{sac} 9-1^{-\%}$ and $\operatorname{sac} 9-3^{--}$ compared to WT plants (Figure 1B to 1D). To confirm that the phenotype observed was due to the lossof-function of SAC9, we generated Arabidopsis lines expressing SAC9 fused to a fluorescent protein (mCIT-SAC9 and TdTOM-SAC9) under SAC9 native promoter (SAC9pro) or the UBIQUITIN10 promoter (UBQ10pro), respectively (Figure 1). To assess the biological relevance of SAC9 phosphatase activity, we also generated a mutated version of SAC9 in the C459 catalytic cysteine into an Alanine (mCIT-SAC9 ${ }^{\mathrm{C} 459 \mathrm{~A}}$ ) from C-x(5)-R-[T/S] conserved catalytic motif in the SAC domain (Hsu and Mao, 2015, 2013, Figure 1 and Supplemental Figure 1A). We found that both SAC9pro:mCIT-SAC9 and UBQ10pro:TdTOM-SAC9 rescued sac9-3\% mutant root phenotype while SAC9pro:mCIT-SAC9C459A did not, indicating that i) the root phenotypes described above are indeed caused by SAC9 loss-offunction, ii) N-terminally tagged SAC9 proteins are functional, and iii) SAC9 phosphatase activity is required for SAC9 function (Figure 1B to 1D).

\section{SAC9 localizes to a population of early endosomes close to the plasma membrane}

Some phosphoinositide-phosphatases such as Metazoan Sac1 and yeast Sac1p, are able to dephosphorylate in vitro several phosphoinositide species, but display a narrower specificity in vivo (Hughes et al. 2000; Guo et al. 1999; Rivas et al. 1999). Also, some enzymes involved in phosphoinositide metabolism, such as the yeast PI 4-kinases Stt4p and Pik1p, specifically impact distinct pools of a given phosphoinositide species depending on their subcellular localization (Roy and Levine 2004; Yoshida et al. 1994; Flanagan et al. 1993). Using stable transgenic lines expressing the functional SAC9pro:mCIT-SAC9 and Ub10pro:TdTOM-SAC9 constructs, we assessed the subcellular distribution of SAC9 in rescued $\operatorname{sac} 9-3^{-/}$homozygous plant using live-cell fluorescence imaging. In meristematic epidermal cells of Arabidopsis roots, mCIT-SAC9 and TdTOM-SAC9 were mainly soluble and excluded from the nucleus (Supplemental Figure 1B). At the cortex of the cell, in close vicinity to the plasma membrane, mCIT-SAC9 localized to a cortical population of mobile dotty structures (Figure 2A, 2B Supplemental Movie 1). We observed that mCIT-SAC9 ${ }^{\mathrm{C} 459 \mathrm{~A}}$ was less soluble with a three-fold increase in the number of mCIT-SAC $9^{\text {C459A }}$ labeled dotty structures compared with the signal collected for the functional fusion proteins mCIT-SAC9 and TdTOM-SAC9 (Figure 2C to 
117 2E). This result suggests that the phosphoinositide phosphatase activity is required for the dynamic 118 interaction of SAC9 with intracellular membranes. Co-visualization of TdTOM-SAC9 and mCIT119 SAC9 $^{\mathrm{C} 459 \mathrm{~A}}$ (Figure $2 \mathrm{~F}$ ) in Col-0 background demonstrated that all TdTOM-SAC9 dotty structures 120 colocalized with mCIT-SAC9 ${ }^{\mathrm{C} 459 \mathrm{~A}}$ at the cortex of the cell, indicating that the catalytic activity of SAC9 121 is only partially required for SAC9 localization. When imaging cells in their cortical part close to the plasma membrane, the mCIT-SAC9 ${ }^{\text {C459A }}$ signal was concentrated in intracellular compartments at the close vicinity with the plasma membrane labelled by the hydrophobic protein Lti6b-2xmCH (Figure $2 \mathrm{G})$. These results suggest a function for SAC9 in regulating phosphoinositide homeostasis either at or in the close vicinity of the plasma membrane.

We next investigated the nature of the intracellular structures labeled by mCIT-SAC9. Both mCITSAC9 and mCIT-SAC9 ${ }^{\text {C459A }}$ colocalized with the amphiphilic styryl dye (FM4-64) stained endosomal compartments at the cell's cortex, just beneath the plasma membrane (Figure 3A and 3B). We observed that Brefeldin A (BFA) treatment led to the aggregation of mCIT-SAC9 and mCIT-SAC9 ${ }^{\mathrm{C} 459 \mathrm{~A}}$ into BFA bodies (Figure 3C and 3D). Since early endosomes/TGN (EE/TGN) are sensitive to BFA while late endosomes (LE/MVB) are not (Takagi and Uemura 2018), this result suggest that both functional and catalytically dead SAC9 fusion proteins localize to endosomes and are likely part of the early steps of endocytic trafficking pathway.

To get more precise insights into the SAC9's localization at the TGN, we crossed Arabidopsis lines expressing fluorescent tagged SAC9 and SAC9 ${ }^{\mathrm{C} 459 \mathrm{~A}}$ proteins with endomembranes markers (Geldner et al. 2009). Using live-cell imaging in root meristematic cells, we observed that mCIT-SAC9 colocalized with TGN markers (CLC2-RFP > 79\% colocalization; mCH-RabA1g >91\%, mCH-VTI12 ${ }^{126-222}>67 \%$; Figure 3C, 3E and 3F). The colocalization of mCIT-SAC9 with these TGN markers was only partial since mCIT-SAC9 was predominantly observed in the cortical section of the cell (Figure 2A), at the close vicinity to the plasma membrane, whereas classical TGN markers are not restricted to the cell cortex (Figure 3E and 3F). This was even more striking when localizing the fluorescent tagged SAC9

142 together with mCH-RabD1 ( $<26 \%$ colocalization, Figure $3 \mathrm{E}$ and $3 \mathrm{~F})$ that also localizes at TGN.

143 Eventually, mCIT-SAC9 showed very weak colocalization with late endosome (LE/MVB) marker 144 (mCH-RabF2a $<17 \%$, Figure 3E and 2F), and with the Golgi marker (mCH-Got $1 \mathrm{p}<1 \%$, Figure 3E and 145 3F). Similarly, mCIT-SAC9 ${ }^{\text {C459A }}$ strongly colocalized with CLC2-RFP and mCH-RAB-A1g markers, 146 whereas it colocalized much weakly with $\mathrm{mCH}-\mathrm{RabD} 1$ and did not colocalized with the Golgi marker 147 (Figure 3C, 3G and 3H). This confirmed that SAC9 and SAC9 ${ }^{\mathrm{C} 459 \mathrm{~A}}$ fusion proteins localized to the 148 TGN/EE, with the noticeable difference that SAC9 localization in endomembrane compartments was 149 restricted to the cortex of the cell, suggesting a role of SAC9 in PI(4,5) $\mathrm{P}_{2}$ homeostasis between the 150 plasma membrane and early endosomal compartments. 
It was previously reported that Arabidopsis sac9-1 loss-of-function mutant had a diminution of PI4P and a three-fold accumulation of $\mathrm{PI}(4,5) \mathrm{P}_{2}$, suggesting that SAC9 has a $\mathrm{PI}(4,5) \mathrm{P}_{2}$ 5-phosphatase catalytic activity (Williams et al. 2005). In order to visualize the effect of the perturbation of the PIPmetabolism in the absence of SAC9, we introgressed two independents $\mathrm{PI}(4,5) \mathrm{P}_{2}$ biosensors (Simon et al. 2014) into sac $9-3^{-/}$genetic background. As expected, both $\mathrm{PI}(4,5) \mathrm{P}_{2}$ biosensors strictly labeled the

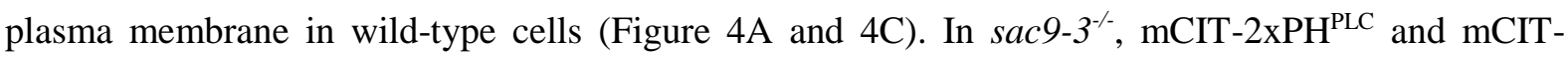
TUBBYc not only labeled the plasma membrane, but also decorated cortical intracellular dotty structures (Figure 4A and 4C). Thus, SAC9 is required for $\mathrm{PI}(4,5) \mathrm{P}_{2}$ restriction at the plasma membrane. We also observed an increase of the number of intracellular compartments labeled by the PI4P biosensors (Simon et al. 2014; Simon et al. 2016) mCIT-PH ${ }^{\text {FAPP1 }}$ and mCIT-P4M ${ }^{\text {SidM }}$, but not for mCIT$\mathrm{PH}^{\mathrm{OSBP}}$ (Figure 4B and 4C). These results is consistent with a diminution of the PI4P pool at the plasma membrane and therefore the relocalization of the PI4P biosensor at intracellular compartments, as previously reported (Simon et al. 2016). The subcellular localization of PI3P sensors (mCIT-FYVE ${ }^{\text {HRS }}$ and $\mathrm{mCIT}_{-} \mathrm{PHOX}^{\mathrm{p} 40}$ ) was identical between Col-0 and $s a c 9^{-/}$cells (Figure 4C, Supplemental Figure 2A). We also detected a slight but significant decrease in the density of intracellular compartments decorated by mCIT-C2 ${ }^{\text {Lact }}$ phosphatidylserine biosensor in sac9- $3^{-/-}$(Figure 4C; Supplemental Figure 2B). Taken together, these results indicate that SAC9-depletion leads to a massive change in $\mathrm{PI}(4,5) \mathrm{P}_{2}$ subcellular patterning, which is present on intracellular cortical structures instead of only being present at the plasma membrane.

Previous investigation of the fine structure in $S A C 9$ mutant allele reported a massive accumulation of vesicles, presumably containing cell wall, at the close vicinity to the plasma membrane (Vollmer et al. 2011). When co-imaging $2 \mathrm{xmCH}^{-2} \mathrm{xPH}^{\mathrm{FAPP} 1}$ together mCIT-TUBBYc in $s a c 9-3^{--}$(Figure 4D), the dotty structures decorated by the $\mathrm{PI}(4,5) \mathrm{P}_{2}$ biosensor — but not with the PI4P biosensor - were observed at the cortex of the cell, at the close vicinity with the plasma membrane (Figure 4D upper panel and $4 \mathrm{E}$ ), whereas those structures were rarely observed in the internal part of the cell (Figure 4D lower panel and $4 \mathrm{E})$. Therefore dotty structures containing $\mathrm{PI}(4,5) \mathrm{P}_{2}$ were associated with PI4P labelled complements but they did not strictly overlap. Confocal imaging of sac9-3/- mutant co-expressing mCIT-TUBBYc with endosomal markers revealed that the dotty structures containing $\mathrm{PI}(4,5) \mathrm{P}_{2}$ were found associated with FM4-64 endocytic tracer as well as TGN markers (Supplemental Figure 3A-B). Furthermore, BFA treatment efficiently induced $2 \mathrm{xmCH}^{-2} \mathrm{xPH}^{\mathrm{FAPP} 1}$ positive BFA bodies in sac $9-3^{-}$ but did not affect the distribution of mCIT-TUBBYc compartments in the same cells (Supplemental Figure $3 \mathrm{C})$. Therefore, $\mathrm{PI}(4,5) \mathrm{P}_{2}$ intracellular compartments in $s a c 9-3^{-/}$are devoid of any ARF GTPase activated by BFA sensitive ARF-GEF. In vivo time-lapse imaging of $\mathrm{PI}(4,5) \mathrm{P}_{2}$ biosensor mCIT- 
187

in the cortex of root epidermal cells, hence, behaving like intracellular compartments (Supplemental Figure 3D, Supplemental movie 2).

We next addressed the turnover and the origin of the cortical intracellular $\mathrm{PI}(4,5) \mathrm{P}_{2}$ compartment observed in $\operatorname{sac} 9-3^{-\%}$. We previously showed that short-term treatment (15-30 min) with phenyl arsine oxide (PAO), a pan PI 4-kinases inhibitor, significantly depletes PI4P (Figure 5E) but not PI(4,5) $\mathrm{P}_{2}$ pools at the plasma membrane of plant cells, whereas longer treatment (> $60 \mathrm{~min}$ ) affects the synthesis of both lipids (Figure 5A, Platre et al., 2018; Simon et al., 2016). We used this pharmacological approach to test the effect of the inhibition of either PI4P, or both $\mathrm{PI} 4 \mathrm{P}$ and $\mathrm{PI}(4,5) \mathrm{P}_{2}$ synthesis, on sac9$3^{-/}$anomalous $\mathrm{PI}(4,5) \mathrm{P}_{2}$ intracellular compartments (Figure 5B to 5E). Solubilization of mCIT-PH ${ }^{\mathrm{FAPP} 1-}$ ${ }^{\text {E50A }}$ PI4P biosensor in $s a c 9-3^{-/}$cells treated for either 30 or 120 min with PAO confirmed the efficient PI4P depletion in both conditions (Figure 5E). Solubilization of mCIT-TUBB Yc PI(4,5) $\mathrm{P}_{2}$ biosensor in WT after $120 \mathrm{~min}$ of $\mathrm{PAO}$ exposure, but not after $30 \mathrm{~min}$, confirmed that an efficient $\mathrm{PI}(4,5) \mathrm{P}_{2}$ depletion occurred only for the longest treatment (Figure 5B and 5C). 30 min PAO treatment did not affect anomalous sac9-3- $\mathrm{PI}(4,5) \mathrm{P}_{2}$ compartments, but 120 min $\mathrm{PAO}$ treatment significantly reduced the number of anomalous $\mathrm{PI}(4,5) \mathrm{P}_{2}$ compartments compared to both 120 min mock treatments or $30 \mathrm{~min}$ short treatment (Figure 5B and 5C), showing that intracellular $\mathrm{PI}(4,5) \mathrm{P}_{2}$ compartments in $s a c 9-3^{-/}$are dependent on the PI4P synthesis, itself substrate for $\mathrm{PI}(4,5) \mathrm{P}_{2}$ production.

\section{SAC9 is required for efficient endocytic trafficking}

Because of the specific localization of SAC9 at the cortex of the cell and its colocalization with early TGN/EE markers, we wondered whether $\mathrm{PI}(4,5) \mathrm{P}_{2}$ defective patterning in sac $9-3^{--}$correlated with endocytic defects. We counted the number of labeled endosomes following FM4-64 endocytic tracer treatment in cells from WT and sac9-3 ${ }^{-/}$seedlings (Rigal et al. 2015). We observed a significant near two-fold decrease in the number of FM4-64-labelled endosomes per cells in sac $9-3^{-\%}$ compared to WT (Figure 6A and B), that was not caused by smaller cells in $s a c 9-3^{-/}$as the density of FM4-64-labelled endosomes was also strongly and significantly decreased compared to WT (Supplemental Figure 4).We inhibited recycling with BFA, and used FM4-64 tracer to monitor the endocytosis by measuring the number of BFA bodies labeled by FM4-64 in Col-0 and sac9- $3^{-\%}$. We observed significantly less FM464-labelled BFA bodies per cells in sac9-3/- compared to wild-type (Figure $6 \mathrm{C}$ and D), confirming the lower rate of endocytosis in this mutant. We then assessed whether SAC9 depletion affected the trafficking of cargo proteins. We, therefore, performed another BFA assay, but using the integral membrane protein PIN-FORMED2 fused with GFP (PIN2-GFP) which localizes at the plasma membrane and in intracellular organelles as it continuously recycles (Armengot et al. 2016). We observed significantly less PIN2-GFP-labelled BFA bodies per cell in $s a c 9-3^{-\%}$ compared to WT (Figure 
6E and F). PIN2-GFP being partially located on intracellular organelles before BFA treatment, the effect observed may, therefore, indicate an endocytic defect as supported by the others experiments, , and/or a more general defect in trafficking in $\operatorname{sac} 9-3^{-\frac{1}{}}$.

To gain further insights into the function of SAC9 in bulk endocytosis, we investigated the sensitivity of the sac 9 mutant to pharmacological inhibition of endocytosis. To this end, we used the recently described ES9-17, which is a specific inhibitor of clathrin-mediated endocytosis (Dejonghe et al. 2019). We treated wild-type and sac9-3\% seedlings with ES9-17 for $180 \mathrm{~min}$ and labeled the plasma membrane and endosomes with FM4-64. Cells from both mock-treated wild-type and sac9-3 ${ }^{-/}$seedlings did not display any obvious defect (Figure 6G). On the contrary, we observed dome-shaped plasma membrane invaginations in ES9-17 long-term treatment of Col-0 seedlings, almost exclusively in elongating or differentiated cells (epidermal or root cap cells), substantiating the possibility that these invaginations constitute read-outs of long term disturb endocytosis (Figure 6G and H). Strikingly, we observed a much higher number of dome-shaped plasma membrane invagination in cells from ES9-17 treated sac9$3^{-/}$(Figure 6G and $\mathrm{H}$ ), showing that SAC9 depletion causes over-sensitivity to inhibition of endocytosis. Hypersensitivity to endocytosis inhibition, decreased internalization of the bulk endocytic tracer FM464 and defects in PIN2 protein trafficking together indicate that endocytic trafficking is impacted in the absence of SAC9.

\section{SAC9 is required for SH3P2 localization at the plasma membrane.}

To gain some insights into SAC9 function, we next screened for SAC9 interactors using a yeast two hybrid assay against a universal Arabidopsis normalized dT library (ULTImate Y2H SCREEN, hybrigenics). As a bait, we used a portion of SAC9 (AA 499 to 966), which includes the WW domain, a putative protein-protein interaction platform. Out of 59.6 million screened interaction, we recovered and sequenced 260 independent clones corresponding to 107 different proteins. However, among these proteins, most were classified as proven artifact or low confidence interaction and only three candidates $(2.8 \%)$ were ranked as very high confidence in the interaction (Supplemental Table 2). Among the high confident interaction candidate, we identified 11 clones corresponding to SH3P2 (5 independent clones). In the yeast-two-hybrid screen, the selected interaction domain identified for SH3P2, corresponds to the C-terminal part of the proteins (aa 213-368), which includes the SH3 domain (Figure 7A). We decided to focus on this candidate because, like SAC9, SH3P2 is linked to both clathrinmediated endocytosis and membrane phosphoinositides. Indeed, SH3P2 i) colocalizes with clathrin light chain, ii) cofractionates with clathrin-coated vesicles (Nagel et al. 2017), and iii) coimmunoprecipitates in planta with clathrin heavy chain (Nagel et al. 2017), clathrin light chain 
various phosphoinositides in vitro (Zhuang et al. 2013; Ahn et al. 2017), and its plasma membrane localization is dependent on $\mathrm{PI}(4,5) \mathrm{P}_{2}$ in vivo (Doumane et al. 2021).

Using live cell imaging we observed that fluorescently tagged SAC9 ${ }^{\mathrm{C} 459 \mathrm{~A}}$ and SH3P2 colocalized in a subcortical population of endomembrane compartments (Figure 7BC), probably TGN/EEs (Figure 3E and F). Because SH3P2 was described to play a role at different steps of the trafficking, from the endocytosis at the plasma membrane to autophagy, we next addressed more precisely which pool of SH3P2 was affected in absence of SAC9. Using confocal imaging, we observed a diminution of the signal corresponding to SH3P2-sGFP at the plasma membrane compared to the cytoplasm in sac9 (Figure 7D-E). Thus, consistently with the idea that SAC9 regulates SH3P2 localization at the plasma membrane through its interaction, these results point toward a role of SAC9 in endocytosis.

\section{The endocytic protein T-PLATE has an altered dynamic in the absence of SAC9}

SAC9 is observed at the close vicinity to the plasma membrane and its absence causes a mislocalization of its protein partner $\mathrm{SH} 3 \mathrm{P} 2$, as well as a reduction of the overall endocytosis process. We then assessed if the clathrin-mediated endocytosis at the plasma membrane was affected in absence of SAC9. Using Total Internal Reflection Fluorescence (TIRF) microscopy, we determined the density and dynamic behavior of the endocytic protein from the T-PLATE complex, T-PLATE-GFP, in the sac 9 mutant compared with wild-type plants. Quantitative analysis revealed that the density of T-PLATE-GFP was reduced in sac9-3/- compared with the WT (Figure 8A, B; supplemental movie 3). Analysis of the dynamics of T-PLATE-GFP at the plasma membrane of etiolated hypocotyl revealed a decrease of the dwell time of T-PLATE-GFP at the plasma membrane in the sac 9 mutant compared to the WT. This result is in line with a reduction of the endocytic flow in the absence of SAC9, and suggests that maintaining a strict plasma membrane accumulation of $\mathrm{PI}(4,5) \mathrm{P}_{2}$ is critical for clathrin-mediated endocytosis. 


\section{DISCUSSION}

285

286

287

288

289

290

291

292

293

294

295

296

297

298

299

300

301

302

303

304

305

306

307

308

309

310

311

312

313

314

315

316

Here, we showed that the phosphatase activity of SAC9 is required for its function, and that fluorescent SAC9 protein fusions colocalize with TGN/EE markers in a subpopulation of endosomes close to the plasma membrane. We found that the subcellular patterning of $\mathrm{PI}(4,5) \mathrm{P}_{2}$ is defective in sac 9 mutants, consistent with the idea that SAC9 is a $\mathrm{PI}(4,5) \mathrm{P}_{2}$ 5-phosphatase. In planta, SAC9 interacts and colocalizes with the endocytosis component SH3P2. In the absence of SAC9, and therefore when the patterning of the $\mathrm{PI}(4,5) \mathrm{P}_{2}$ at the plasma membrane and at its close vicinity is affected, SH3P2 no longer localizes at the plasma membrane and the rate of clathrin-mediated endocytosis is significantly reduced. Together, these findings underlie the importance of strictly restricting $\mathrm{PI}(4,5) \mathrm{P}_{2}$ to the plasma membrane during the endocytic process.

\section{SAC9 and phosphoinositide interconversion along the endocytic pathway}

In animal cells, a phosphoinositide conversion cascade has been described through the successive action of phosphoinositide kinases and phosphatases. This cascade starts with $\mathrm{PI}(4,5) \mathrm{P}_{2}$ at the plasma membrane and ends-up with PI3P in the membrane of early endosomes (Noack and Jaillais 2017; Schmid and Mettlen 2013; Abad et al. 2017; Posor et al. 2015; Posor et al. 2013; Shin et al. 2005). Briefly, $\mathrm{PI}(4,5) \mathrm{P}_{2}$ is dephosphorylated at the plasma membrane or during the endocytic process by 5 phosphatase enzymes such as OCRL and synaptojanin (De Matteis et al. 2017) (Cauvin et al. 2016; Nandez et al. 2014; Ben El Kadhi et al. 2011; Posor et al. 2013). PI4P is then phosphorylated into $\mathrm{PI}(3,4) \mathrm{P}_{2}$ inside clathrin-coated pits by a PI3-Kinase (PI3K C2 $\alpha$ ), before being converted into PI3P through the action of a PI4P phosphatase on clathrin-coated vesicles (Schmid and Mettlen 2013; Posor et al. 2013). Because both $\mathrm{PI}(4,5) \mathrm{P}_{2}$ and PI3P are essential regulators of endocytic trafficking, this conversion cascade, and in particular the precise recruitment of dedicated enzymes at the right place and at the right time during endocytosis, is of critical importance of clathrin-mediated endocytosis to proceed normally (Noack and Jaillais 2017; Schmid and Mettlen 2013).

Plants have a much simpler endosomal system, where the TGN functions as an early endosome. This hybrid compartment collects endocytic vesicles and redirects cargo proteins either to the plasma membrane for recycling or to late endosomes/vacuole for degradation (Dettmer et al. 2006; Narasimhan et al. 2020; Rodriguez-Furlan et al. 2019). The plant TGN/EE is enriched in PI4P, not PI3P, which instead accumulates in late endosomes (Noack and Jaillais 2020; Simon et al. 2014). Interestingly, we found that i) SAC9 localizes to clathrin-coated vesicles close to the plasma membrane, and ii) the sac9 mutant accumulates $\mathrm{PI}(4,5) \mathrm{P}_{2}$ in vesicular structures at the cortex of the cells. Together, we propose that SAC9 represent the long sought-after enzyme which performs the $\mathrm{PI}(4,5) \mathrm{P}_{2}$-to-PI4P conversion 
during the plant endocytic process (Figure 9). As such, SAC9 is required to erase $\mathrm{PI}(4,5) \mathrm{P}_{2}$ in endosomal membranes and thereby maintains this lipid strictly at the plasma membrane.

\section{Accumulation of $\mathrm{PI}(4,5) \mathrm{P}_{2}$-containing vesicles in the $\operatorname{sac} 9$ mutant}

In the absence of SAC9, $\mathrm{PI}(4,5) \mathrm{P}_{2}$ accumulates inside the cell in what appears to be abnormal compartments that are associated with but independent from TGN/EEs. We can speculate that the prolonged accumulation of $\mathrm{PI}(4,5) \mathrm{P}_{2}$ on clathrin-coated vesicles, and perhaps the lack of PI4P production on these structures, impairs the function of these vesicles. Ultrastructural analyses previously revealed that $\operatorname{sac} 9$ accumulates extra vesicles close to the cell surface (Vollmer et al. 2011). The finding of these unknown subcortical vesicles in $\operatorname{sac} 9$ resonates with our confocal microscopy observations of ectopic $\mathrm{PI}(4,5) \mathrm{P}_{2}$-containing vesicles in this mutant. Importantly, we found that these vesicles are not extensively labeled after a short-term FM4-64 treatment. This suggests that these vesicles are accumulating slowly over time in the sac9 mutants and are not actively exchanging membrane materials with the TGN/EEs or the plasma membrane, at least not in the 30-minute time frame of the FM4-64 pulse labeling experiment. Together, we propose that $\mathrm{PI}(4,5) \mathrm{P}_{2}$ accumulation on endocytic vesicles after scission could lead to an altered dynamics of these vesicles, which may be unable to fuse correctly with TGN/EEs, ultimately leading to their accumulation in the cell cortex (Figure 9).

We observed that the endocytic pathway is partially impaired in absence of SAC9, and that $\operatorname{sac} 9$ was oversensitive to ES9-17-mediated inhibition of endocytosis. In animal cells, membrane protuberances have been reported in cultured cells knocked-out or knock-down for enzymes of $\mathrm{PI}(4,5) \mathrm{P}_{2}$ metabolism (Gurung et al. 2003; Terebiznik et al. 2002; Mochizuki and Takenawa 1999). These protuberances could therefore be a conserved process affected by disturbed $\mathrm{PI}(4,5) \mathrm{P}_{2}$ homeostasis in both plant and animal cells leading to such plasma membrane distortion. It is not the first observation of plasma membrane protuberances in cells where $\mathrm{PI}(4,5) \mathrm{P}_{2}$ homeostasis is affected: upon PIP5K6 over-expression in pollen tubes, which increases $\mathrm{PI}(4,5) \mathrm{P}_{2}$ levels, plasma membrane invaginations also occurs. The authors elegantly demonstrated that these plasma membrane distortions are due to clathrin-mediated endocytosis defects (Zhao et al. 2010). These structures were also reported when inducible depletion of $\mathrm{PI}(4,5) \mathrm{P}_{2}$ at the plasma membrane of root cells was performed using the iDePP system (Doumane et al. 2021), suggesting that the tight regulation of the $\mathrm{PI}(4,5) \mathrm{P}_{2}$ metabolism is important for the integrity of the plasma membrane. Previous study on the cellular organization of the primary roots of sac9-1 seedlings at ultrastructural level reported the excessive membrane material either in direct contacts or close to the wall forming the protuberances (Vollmer et al. 2011). The irregular cell wall deposition in the $\operatorname{sac} 9$ mutant leads to cell wall ingrowths, coined "whorl-like structures" (Vollmer et al. 2011). We 
propose that such protuberances could be a readout of long-term endocytic defects, for instance caused by an excess of plasma membrane due to unbalanced exocytosis. If so, the appearance of plasma membrane protuberances upon $\mathrm{PI}(4,5) \mathrm{P}_{2}$ metabolism perturbation could be an additional indication of disturbed endocytosis.

\section{How could SAC9 regulate endocytosis?}

We observed that the endocytic pathway is partially impaired in the absence of SAC9. We envision several scenarios to explain these endocytic defects. They are not mutually exclusive and ultimately, it would not be surprising if the sac 9 endocytic phenotype results from a combination of altered cellular pathways relying, directly or indirectly, on the precise spatio-temporal regulation of anionic lipid homeostasis. First, as mentioned in the paragraph above, the sac 9 mutant likely accumulates ectopic vesicle following endocytosis. These vesicles trap membrane components inside the cell, which may overall impact the endocytic process. In addition, it is possible that the localization or dynamics of $\mathrm{PI}(4,5) \mathrm{P}_{2}$ binding proteins, which regulate clathrin-mediated endocytosis, could be impacted, as we observed for SH3P2 and T-PLATE (Zhuang et al. 2013; Yperman et al. 2021b; Yperman et al. 2021a). Other proteins from the T-PLATE complex also interact with anionic lipids, including $\mathrm{PI}(4,5) \mathrm{P}_{2}$, and could be affected in sac9 (Yperman et al. 2021b; Yperman et al. 2021a). Furthermore, the dynamics of dynamin-related proteins, which contain a lipid-binding plekstrin homology domain, and the AP2 adaptor complex, which relies on $\mathrm{PI}(4,5) \mathrm{P}_{2}$ for localization in planta (Doumane et al. 2021), could also be altered in $s a c 9$. It was also recently reported that perturbation of clathrin-containing vesicles at the TGN/EEs also impacts clathrin-mediated endocytosis (and conversely) (Yan et al. 2021). It is thus possible that perturbing phosphoinositides metabolism after the scission of clathrin-coated vesicles from the plasma membrane impacts the dynamics of clathrin-mediated endocytosis at the cell surface in an indirect way, for example because of slowed recycling of the clathrin pool or other endocytic components at the surface of TGN/EEs.

It is also important to note that bulk endocytosis in general and clathrin-mediated endocytosis in particular are still going-on in the sac9 mutant, albeit at a reduced rate. Thus, while $\mathrm{PI}(4,5) \mathrm{P}_{2}$ strict exclusion from intracellular membranes is important for the endocytic process, the plant membrane trafficking system appears to be extremely resilient, as it manages to operate despite the accumulation of these membrane of mixed identity inside the cell. Here, we can speculate that SAC9 may not be the only 5-phosphatase enzyme that can control $\mathrm{PI}(4,5) \mathrm{P}_{2}$ homeostasis during endocytosis. In addition, while $\mathrm{PI}(4,5) \mathrm{P}_{2}$ is the main phosphoinositide regulating the recruitment of endocytic regulators in animals, it is likely not the case in plants. Indeed, PI4P, not $\mathrm{PI}(4,5) \mathrm{P}_{2}$, is the major anionic lipids that 
385

386

387

388

389

390

391

392

393

394

395

396

397

398

399

400

401

402

403

404

405

406

407

408

409

410

411

412

413

414

415

416

417

endocytic proteins in plants (Yperman et al. 2021b; Yperman et al. 2021a). In addition, phosphatidic acid (PA) is also important to drive the electrostatic field of the plasma membrane (Platre et al. 2018) and PA could be involved in the localization of AtEH1/Pan1, a component of the T-PLATE complex (Yperman et al. 2021a).

\section{Limitation of the study}

SAC9 was previously proposed to act as a $\mathrm{PI}(4,5) \mathrm{P}_{2}$ 5-phosphatase in planta, mainly because the sac9 mutant accumulates $\mathrm{PI}(4,5) \mathrm{P}_{2}$ (Williams et al. 2005). We found an accumulation of $\mathrm{PI}(4,5) \mathrm{P}_{2}$ sensors inside the cells in sac9, which is fully consistent for a 5-phosphatase enzyme. However, we could not confirm this activity in vitro. This is mainly due to problems in purifying SAC9 catalytic domain in sufficient quantity. Yet, it represents a weakness of our study that we should keep in mind. Indeed, although this is not the most parsimonious explanation, it is possible that SAC9 is not a 5phosphatase and that instead it controls the localization or activity of another enzyme bearing this catalytic activity. Nonetheless, the fact that catalytically inactive mCIT-SAC9 ${ }^{\mathrm{C} 459 \mathrm{~A}}$ fusion protein does not rescue sac 9 macroscopic phenotype suggests that SAC9 phosphatase activity is required for its function.

To explain the endocytic defects observed in the sac 9 mutant, we mainly focused on $\mathrm{PI}(4,5) \mathrm{P}_{2}$ mispatterning. However, biochemical measurements also showed that the sac 9 mutant accumulates less PI4P than its wild-type counterpart. Given the importance of PI4P for plant cell function (Noack et al. 2020; Simon et al. 2016), it is possible that PI4P rather than (or in combination with) $\mathrm{PI}(4,5) \mathrm{P}_{2}$ defects are involved in the $\operatorname{sac} 9$ phenotypes. Given that phosphoinositide metabolism is highly intricate, we fully recognize that it is difficult to fully untangle the specific involvement of each lipid in the observed phenotypes. In addition, the SAC9 protein may carry specific functions outside of its catalytic activity. For example, SAC9 directly interacts with SH3P2, yet the physiological relevance of this interaction for both SAC9 and SH3P2 function remains unclear. Structure-function analyses aiming at dissecting this interaction will be instrumental to clarify this point. In addition, the exact function of SH3P2 in endocytosis is also elusive and it will be important to analyze it in details in the future. Finally, one of the clear limitations in interpreting the $s a c 9$ phenotype, which is common to most genetic approaches, is the accumulation of defects over a long-time period in the mutant. As such, it is impossible to pinpoint toward direct or indirect effects of $\mathrm{PI}(4,5) \mathrm{P}_{2}$ mis-patterning on the cellular and developmental phenotypes of this mutant. Future studies, aiming at rapidly manipulating SAC9 function and localization in an inducible manner will be instrumental in disentangling the direct and indirect effects of SAC9 on lipid dynamics and endocytosis regulation. 


\section{Growth condition and plant materials}

420 Arabidopsis thaliana Columbia-0 (Col-0) accession was used as wild-type (WT) reference genomic 421 background throughout this study. Arabidopsis seedlings in vitro on half Murashige and Skoog (1/2 MS) 422 basal medium supplemented with $0.8 \%$ plant agar ( $\mathrm{pH} 5.7$ ) in continuous light conditions at $21{ }^{\circ} \mathrm{C}$. 423 Plants were grown in soil under long-day conditions at $21{ }^{\circ} \mathrm{C}$ and $70 \%$ humidity $16 \mathrm{~h}$ daylight.

\section{Cloning}

SAC9 promoter (SAC9pro; $800 \mathrm{bp)}$ ) was amplified from Col-0 genomic DNA using SAC9prom_fwd_gb TTGTATAGAAAAGTTGCTATTGAAAAAAGATAGAGGCGCGTG and SAC9prom_rev_gb TTTTTTGTACAAACTTGCCTGAGCTCAGGACCAAGCGG primers and the corresponding PCR product was recombined into $P D O N R-P 1 R P 4$ (life technologies www.lifetechnologies.com/) vector by BP reaction to give SAC9pro/pDONR-P1RP4. The $m C I T$ and TdTOM containing vectors cYFPnoSTOP/pDONR221 and TdTOMnoSTOP/pDONR221 were described before (Simon et al., 2014; Jaillais et al., 2011).

The genomic sequence of SAC9 (At3g59770) was amplified by PCR using 7-day old Arabidopsis seedlings

gDNA as template and the

SAC9-B2R primers. The corresponding PCR product was recombined into $p D O N R-P 2 R P 3$ vector by BP reaction to give $S A C 9 g / p D O N R-P 2 R P 3$.

$439 S A C 9^{\mathrm{C} 459 \mathrm{~A}}$ mutation was obtained by site-directed mutagenesis using the partially overlapping SAC9440 C459A-F TACGTTTTAACGCTGCTGATTCCTTGGATCGAACAAATGC and SAC9-C459A-R 441 AGGAATCAGCAGCGTTAAAACGTATCACCCCATTTTGATGTG primers on $S A C 9 \mathrm{~g} / \mathrm{pDONR}$ $442 \quad P 2 R P 3$.

443 Final destination vectors were obtained using three fragments LR recombination system (life 444 technologies, www.lifetechnologies.com/) using pB7m34GW destination vector (Karimi et al. 2007). 445 The following reactions were set-up to generate the corresponding destination vectors: 446 UBQ10prom:tdTOM-SAC9g/pH, SAC9prom:mCIT-SAC9g/pB, pAtSAC9:mCIT-SAC9gDEAD/pB, 447 SAC9prom:TdTOM-SAC9g DEAD/pH (Supplemental Table 1). 


\section{$449 \quad$ FM4-64 staining and drug treatments}

450 Seedlings were incubated in wells containing $1 \mu$ M FM4-64 (Life Technologies T-3166; from a stock

451

452

453

454

455

456

457

458

459

460

461

462

463

464

465

466

467

468

469

470

471

472

473

474

475

476

477

478 solution of $1.645 \mathrm{mM}=1 \mathrm{mg} / \mathrm{ml}$ in DMSO) in half Murashige and Skoog ( $1 / 2 \mathrm{MS})$ liquid basal medium without shaking for $30 \mathrm{~min}$ and in dark. Seedlings were then mounted in the same medium and imaged within a $10 \mathrm{~min}$ time frame window $(1 \mathrm{~h} \pm 5 \mathrm{~min})$.

Seedlings were incubated in wells containing Brefeldin A (BFA; Sigma B7651) applied at $50 \mu \mathrm{M}$ (from a stock solution of $30 \mathrm{mM}$ in DMSO), or a corresponding volume of DMSO as 'mock' treatment, dissolved in liquid $1 / 2$ MS for one hour in dark without shaking before mounting in the same medium and imaging. For co-treatment with $50 \mu \mathrm{M}$ BFA and $1 \mu \mathrm{M}$ FM4-64, FM4-64 and BFA were added at the same time. Imaging was performed within a $14 \mathrm{~min}$ time frame window $(1 \mathrm{~h} \pm 7 \mathrm{~min})$.

For PAO treatment, seedlings were incubated in wells containing $30 \mu \mathrm{M}$ PAO (Sigma P3075, www.sigmaaldrich.com, PAO stock solution at $60 \mathrm{mM}$ in DMSO), or a volume of DMSO as mock treatment, during the indicated time. Roots were imaged within a 10 min time frame window around the indicated time. The PAO effects on the localization of our biosensors were analyzed by counting manually the number of labelled compartments per cell.

ES9-17 was stored at $-20^{\circ} \mathrm{C}$ as a $30 \mathrm{mM}$ stock solution in DMSO. Seedlings were incubated in dark without shaking for the indicated duration $( \pm 7 \mathrm{~min}$ ) in liquid $1 / 4 \mathrm{MS}(\mathrm{pH} 5.7)$ in wells containing $1 \%$ DMSO to help solubilization of ES9-17, and either $1 \mu \mathrm{M}$ ES9-17 or the corresponding additional volume of DMSO (mock treatment). For $1 \mu$ M ES9-17 and $1 \mu$ M FM4-64, FM4-64 was added 30 min after the ES9-17 (the indicated time corresponds to ES9-17 exposure).

\section{Western-Blot}

To verify that SAC fusion proteins were present in the plant cells, leaves from 1-month-old plants were vacuum infiltrated three times with $100 \mu \mathrm{M}$ MG132 (inhibitor of proteasome). Treated leaves were grind in liquid nitrogen, and ground material resuspended in $4 \mathrm{ml}$ of extraction buffer $(100 \mathrm{mM}$ Tris- $\mathrm{HCl}$ pH 7.5, $150 \mathrm{mM} \mathrm{NaCl}, 5 \mathrm{mM}$ EDTA, 5\% glycerol, $10 \mathrm{mM}$ DTT, 0.5\% Triton X-100, 1\% Igepal and $1 \%$ protease inhibitors (Sigma) into $1 / 2$ MS $100 \mu$ M MG132) and centrifuged at $17896 \mathrm{~g}$ for $40 \mathrm{~min}$ at $4^{\circ} \mathrm{C}$ to obtain the total protein extract in the supernatant. $1 \mathrm{ml}$ of the total protein extract was incubated 20 min with $50 \mu \mathrm{L}$ of magnetic protein G Dynabeads (Millipore) fused to a GFP monoclonal antibody (1/500 in PBS $0.002 \%$ tween). Beads, antibodies and antibodies bund proteins were 
magnetically precipitated on columns, eluted and denatured in $40 \mu \mathrm{L}$ of Lamelli buffer $2 \mathrm{X}$ at $95^{\circ} \mathrm{C}$ for 5 min. $20 \mu \mathrm{L}$ of immunoprecipitated proteins were loaded onto $7.5 \%$ polyacrylamide gel, run for 105 $\min$ at $125 \mathrm{~V}$ and blotted on nitrocellulose membranes over-night at $20 \mathrm{~V}$ on ice. Membranes were blocked in $5 \%$ milk dissolved in TBST buffer (10 mM Tris-HCL, $150 \mathrm{mM} \mathrm{NaCL}, 0.05 \%$ Tween20) for $2 \mathrm{~h}$ at $4^{\circ} \mathrm{C}$. mCIT tagged proteins were revealed by using respectively GFP monoclonal antibody $(1 / 1000$ in $5 \%$ milk) as primary antibodies and anti-mousse IgG-HRP conjugated secondaries antibodies (1/5000 in TBST). Finally tagged proteins were detected by chemiluminescence using ECL, substrate to HRP enzyme, revelation.

\section{Live cell imaging}

489

Most images (see exceptions below) were acquired with the following spinning disk confocal microscope set up: inverted Zeiss microscope (AxioObserver Z1, Carl Zeiss Group, http://www.zeiss.com/) equipped with a spinning disk module

(CSU-W1-T3, Yokogawa, www.yokogawa.com) and a ProEM+ 1024B camera (Princeton Instrument,

493 http://www.princetoninstruments.com/) or Camera Prime 95B (www.photometrics.com) using a 63x 494 Plan-Apochromat objective (numerical aperture 1.4, oil immersion). GFP and mCITRINE were excited 495 with a $488 \mathrm{~nm}$ laser $(150 \mathrm{~mW})$ and fluorescence emission was filtered by a 525/50 nm BrightLine! 496 single-band bandpass filter (Semrock, http://www.semrock.com/), mCHERRY en TdTOM was excited 497 with a $561 \mathrm{~nm}$ laser $(80 \mathrm{~mW})$ and fluorescence emission was filtered by a $609 / 54 \mathrm{~nm}$ BrightLine! single498 band bandpass filter (Semrock, http://www.semrock.com/ ). For quantitative imaging, pictures of 499 epidermal root meristem cells were taken with detector settings optimized for low background and no 500 pixel saturation. Care was taken to use similar confocal settings when comparing fluorescence intensity 501 or for quantification.

502 Colocalization experiments were performed on an inverted Zeiss CLSM710 confocal microscope or an 503 inverted Zeiss CLSM800 confocal microscope using a 63x Plan-apochromatic objective. Dual-color 504 images were acquired by sequential line switching, allowing the separation of channels by both excitation and emission. In the case of colocalization, we also controlled for a complete absence of

506 channel crosstalk. GFP was excited with a $488 \mathrm{~nm}$ laser, mCIT was excited with a 515nm laser and $507 \mathrm{mCH} / \mathrm{tdTOM}$ were excited with a $561 \mathrm{~nm}$ laser. Imaging was performed in the root epidermis in cells 508 that are at the onset of elongation.

\section{Yeast two-hybrid screen}


511 The yeast two hybrid screen was performed by hybrigenics services (https://www.hybrigenics512 services.com/contents/our-services/interaction-discovery/ultimate-y2h-2), using the ULTImate Y2H 513 screen against their Universal Arabidopsis Normalized library obtained using oligo_dT. A codon

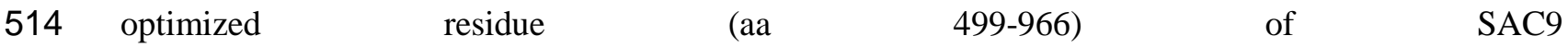

515 gttaataatcaggggggatataacgctcccttccaccgggatgggaaaaaagagctgatgccgtaactggaaaatcatattatatagatcacaata

516 caaagacaacaacatggagtcatccatgtcctgataaaccatggaagagacttgacatgaggtttgaggaatttaagagatcaactatcttatctcctg

517 tgtcagaacttgccgatctttttctgcaacaaggtgatatccatgcaaccetctatactggctcgaaagctatgcacagccaaattctcaacatcttcagt

518 gaagaatcaggagcatttaaacagttttctgcagcacagaaaaacatgaagattacactacagagaagatataaaaatgctatggttgatagttcacg

519 gcaaaaacagctcgagatgtttctgggaatgaggcttttcaagcatcttccatcaattcctgtccagcctttacatgtactttctcgaccatctggtttcttt

520 ctgaaacctgtacctaacatgtccgaaagttccaatgatgggtccagtctgctgagtatcaagaggaaggacataacttggctatgtccacaagctgc

521 agatattgttgaattatttatctatctcagtgagccttgccatgtatgtcaacttctactgaccatatcacacggtgcggatgatttgacatgtccatccact

522 gtggacgtgagaactggacgccacatagaggaccttaaattagttgttgagttagttcaactggattaccgattacctgtaattatgttttctggacagg

523 gtgcttcaataccacgctgtgcaaatggtacaaatcttctggtaccettaccagggccaattagttctgaggatatggctgttactggagctggtgcac

524 gtcttcatgaaaaagatacgtcaagtctttcactgctatatgattttgaagaactagaaggacagttggatttcttaaccegtgtagttgctgttacattttat

525 ccagctggtgctgttagaattcctatgactcttggtcagatagaagtccttggaatttctcttccatggaaaggaatgtttacttgtgaacgtactggagg

526 aagattagctgaacttgcaaggaaaccagatgaagatggaagtccttttcatcttgttctgacttgaatccgtttgctgcaacaacatctttacaggctg

527 aaactgtttccacaccagtacaacagaaggatccetttcccagtaatctgcttgacettttgacaggagaggactcttcttctgacccettcccacaacc

528 agtggtggaatgtattgcaagtggaggcaatgacatgcttgatttcttagacgaagcagttgttgaatatcgcggctctgacactgttcctgacgggtc

$529 \mathrm{t}$ was cloned in a pB66 vector (N-GAL4-bait-C fusion). The screen was performed on $0.5 \mathrm{mM}$ 3AT. 59

530 million interactions were analyzed, and 260 positive clones were sequenced (ATNOR_dT_hgx4515v1

$531 \_$_pB66, Supplemental Table 2.

532

\section{TIRF imaging}

5343 days old etiolated seedlings were used for hypocotyl epidermal cells observations. TIRF-VAEM 535 imaging were made using an ilas2 TIRF microscope (Roper Scientific) with 100x Apo NA 1.46 Oil 536 objective and a Prime 95B camera (Photometrics, https://www.photometrics.com/) and 1.5 coverslips 537 were used (VWR 61-0136). Time lapses were acquired during 300 time-points for 300s (acquisition 538 time 500ms). Spot density were measured using Spot_detector ImageJ macro (Bayle et al. 2017).

539 Particle identification and tracking was performed using ImageJ plugin Trackmate 540 (https://research.pasteur.fr/fr/software/trackmate/) using following parameters: Particle min size 0.5, 541 threshold 50, particles with contrast $>0.04$ were filtered. For tracks filtering 0 gap, min distance between 542 two spots 0.2 .

543

\section{Dissociation indexes}


545 Dissociation indexes of membrane lipid fluorescent biosensors were measured and calculated as 546 previously described (Platre et al., 2018). Briefly, we calculated "indexNoDex", defined as the ratio

547 between the fluorescence intensity (Mean Grey Value function of Fiji software) measured in two

548 elliptical regions of interest (ROIs) from the plasma membrane region (one at the apical/basal plasma

549 membrane region and one in the lateral PM region) and two elliptical ROIs in the cytosol in the mock 550 condition.

\section{Measures, counting and statistical analysis}

553 Primary root length and number of lateral roots were manually measured from pictures. For comparing

554 the primary root length and lateral root density between each genotype, we used a one-way ANOVA

555 and post hoc Tukey HSD pairwise tests (95\% confidence level).

556 For quantitative imaging, pictures of epidermal root meristem cells were taken with detector settings 557 optimized for low background and no pixel saturation. Care was taken to use similar confocal settings 558 when comparing fluorescence intensity. Pseudo-colored images were obtained using the "Green Fire 559 Blue" look-up-table (LUT) of Fiji software (http://www.fiji.sc/). The intracellular compartments 560 ("spots") per cell were automatically counted.

561 We automatically measured the density of intracellular compartments labeled per root for each 562 biosensor, and we used two-sided non-parametric Wilcoxon rank-sum tests to compare Col-0 and sac 9 $5633^{-/}$genotypes. To account for multiple testing, we used a Bonferroni correction and lowered the significance level of each test at alpha $=0.05 / 11=0.004$.

565 Because the signal of mCIT-SAC9 is mainly soluble, no automatic spot detection could be used for 566 colocalization analysis. Therefore, for comparing the number of intracellular compartments containing mCIT-SAC9 or mCIT-SAC $9^{\mathrm{C} 459 \mathrm{~A}}$ protein-fusions per cell across conditions, we manually counted them and used a generalized linear mixed-effect model (Poisson family) accounting for image ID (id est root) as a random factor was used. Since the localization of the marker for the membrane compartment was larger in z compared to the restricted localization of SAC9 (only present at the surface of the cell), we counted the number of mCIT-SAC9 labeled structure which was also labelled by the compartment markers. The same approach was used to deduce the localization of the mutated version of SAC9. We

573 then computed a two-sided Tukey Post hoc tests (function "glht" in multicomp) to specifically compare 574 each pair of conditions.

575 To assess the effect of the inhibitor PAO on anomalous mCIT-TUBBYc intracellular compartments, 576 we manually counted their number per cell. We tested PAO effect and the effect of treatment duration 
577 (30 min and $2 \mathrm{~h}$ ) on the number of marked intracellular compartments using a generalized linear mixed578 effect model (Poisson family) to account for image ID as a random factor. Two sided Post-hoc tests 579 were performed using the package lsmeans. We compared the number of FM4-64 positive 580 compartments in Col-0 and sac $9-3^{-/}$using a generalized linear mixed model (Poisson family) to account 581 for image ID (id est root) as a random factor. The density of FM4-64 labeled compartments was also 582 compared in Col-0 and sac $9-3^{--}$using a linear mixed model accounting for image ID as a random factor; Type II Wald $\chi^{2}$.

584 To compare the effects of BFA on FM4-64 treated Col-0 and sac9-3 ${ }^{--}$, we only compared the BFA 585 treated Col-0 and sac9- $3^{-/}$seedlings using a generalized linear mixed model (Poisson family) with image ID (id est root) as a random factor (Type II Wald $\chi^{2}$ test $: \chi^{2}=33.8, \mathrm{p}<0.001$ ).

587

588

589

590

591

592

593

594

595

596

597

\section{ACKNOWLEDGEMENTS}

599 We are grateful to the SiCE group (RDP, Lyon, France), Dr Yohann Boutté (LBM, Bordeaux, France), 600 Dr Fabrice Besnard and Dr Nicolas Doll (RDP, Lyon, France), Hugo Ducuing (INMG, Lyon, France), 601 Sébastien This (CIRI, Lyon, France) and Augustin Le Bouquin (IGFL, Lyon, France), Dr Sophie 602 Piquerez (IPS2, Paris-Saclay, France) for comments and discussions. We thank Justin Berger, Patrice 603 Bolland, and Alexis Lacroix from our plant facility, and Claire Lionnet from the imaging platform. We 604 are also grateful to Dr Daniël van Damme (VIB, Ghent, Belgium) for sharing with us T-PLATE-GFP 605 and for discussions. We would like to thanks Pr Dr Erika Isono (University of Konstanz, Konstanz, 606 Germany) for sharing SH3P2-sGFP transgenic line with us. We are also grateful to E. Russinova (VIB, 607 Ghent, Belgium) for kindly providing us ES9-17; S. Bednarek for sharing markers and for discussions. 608 This work was supported by two Seed Fund ENS LYON-2016 and LYON-2019 (to MCC), a Junior 609 Investigator grant ANR-16-CE13-0021 (to MCC), ERC no. 3363360-APPL under FP/2007-2013 (to 610 YJ). MD and AL were funded by Ph.D. fellowships from the French Ministry of Research and Higher 611 Education. 


\section{FIGURES}
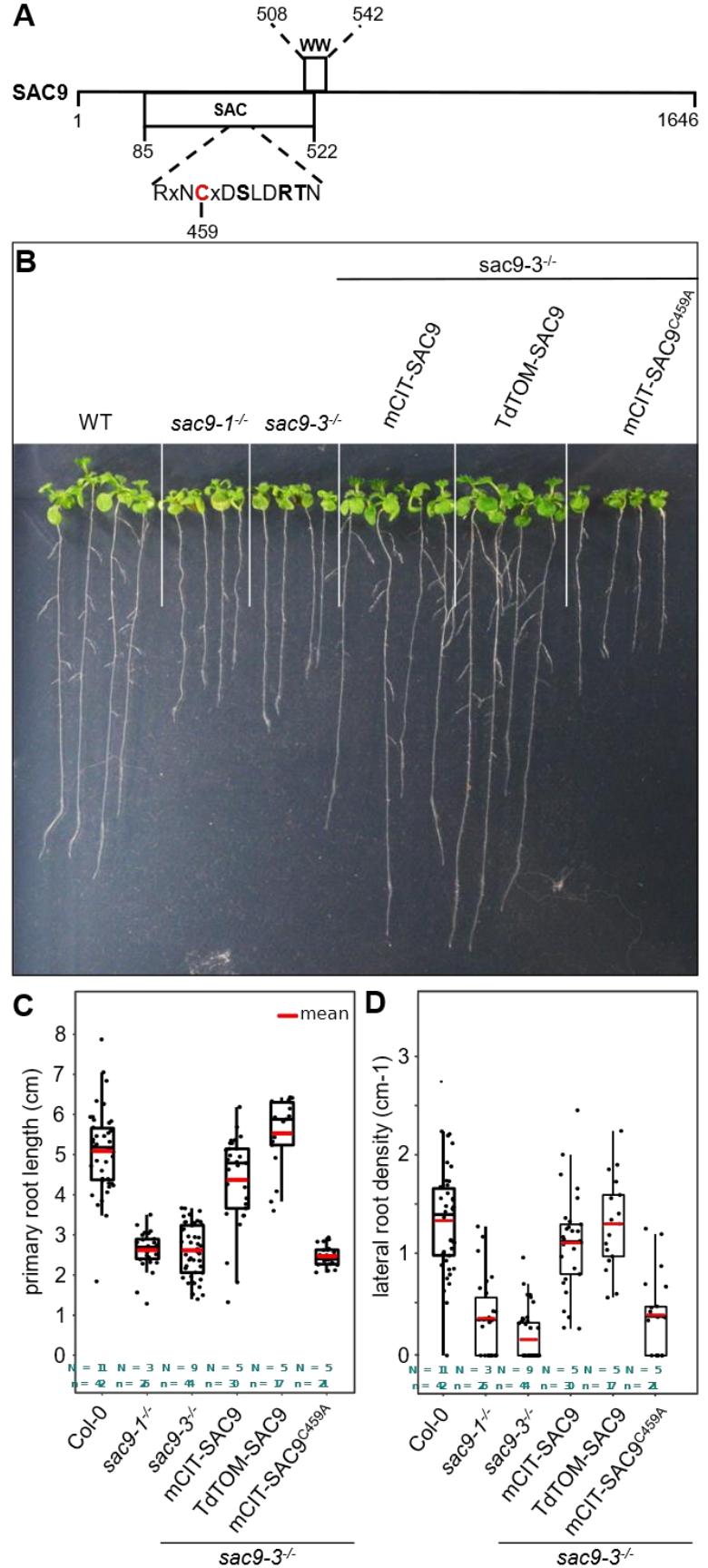

614 Figure 1. Structure-function analysis of SAC9. A, Schematic representation of SAC9 protein. The SAC catalytic domain, as well

615 as the WW domain, are represented. B, Representative images of the macroscopic phenotype observed in (i) wild-type (Col-0), (ii)

616 sac $9-1 \%$ and $s a c 9-3 \%$ loss of function mutants, (iii) sac $\%-3 \%$ complemented lines expressing full-length genomic DNA encoding SAC9

617 fused to fluorescent protein (mCIT-SAC9 and TdTOM-SAC9) or a mutated version of the catalytic cysteine residue within the C-

$618 \mathrm{x}(5)-\mathrm{R}-[\mathrm{TS}]$ catalytic motif in the SAC domain (mCIT-SAC9C459A; right panel). Pictures are taken 12 days post germination (dpg).

619 C, Quantification of primary root length in sac9-3\% homozygous mutants expressing mCIT-SAC9 and TdTOM-SAC9, mCIT-

620 SAC9C459A under the control of the native promoter (SAC9prom). Wild-type (Col-0) seedlings and two independent mutant alleles

621 of $S A C 9$, sac9-1\% and sac9-3\%, are used as controls. D, Same as (C) but for the quantification of the lateral root density (ratio of the number of lateral roots to primary root length). In the plots, middle horizontal bars represent the median, while the bottom and top of each box represent the 25th and 75th percentiles, respectively. At most, the whiskers extend to 1.5 times the interquartile range, excluding data beyond. For range of value under 1,5 IQR, whiskers represent the range of maximum and minimum values. 
bioRxiv preprint doi: https://doi org/10.1101/2021.09.10.459735; this version posted September 12, 2021. The copyright holder for this preprint (which was not certified by peer review) is the author/funder. All rights reserved. No reuse allowed without permission.

A

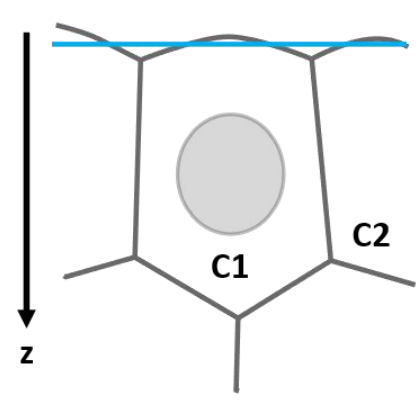

B

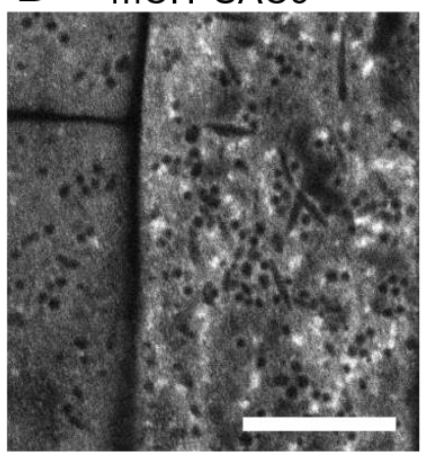

D mCIT-SAC9

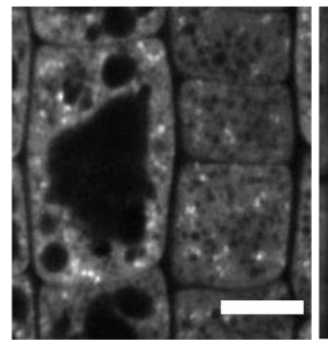

F TdTOM-SAC9
TdTOM-SAC9

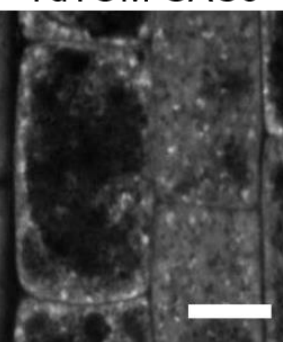

mCIT-SAC9C459A

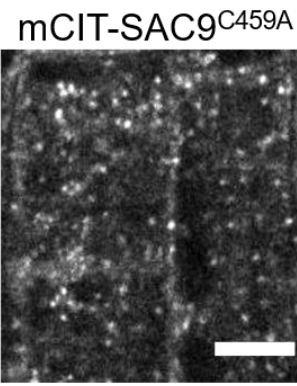

merge

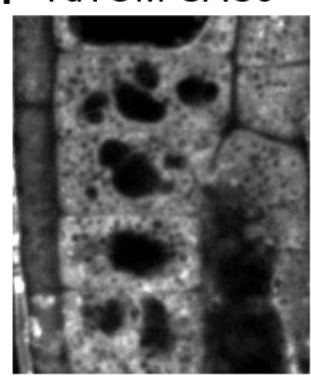

$\mathbf{G}$
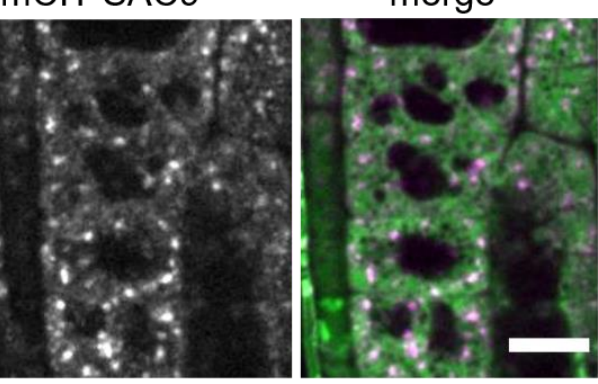

mCIT-SAC9C459A + PM marker
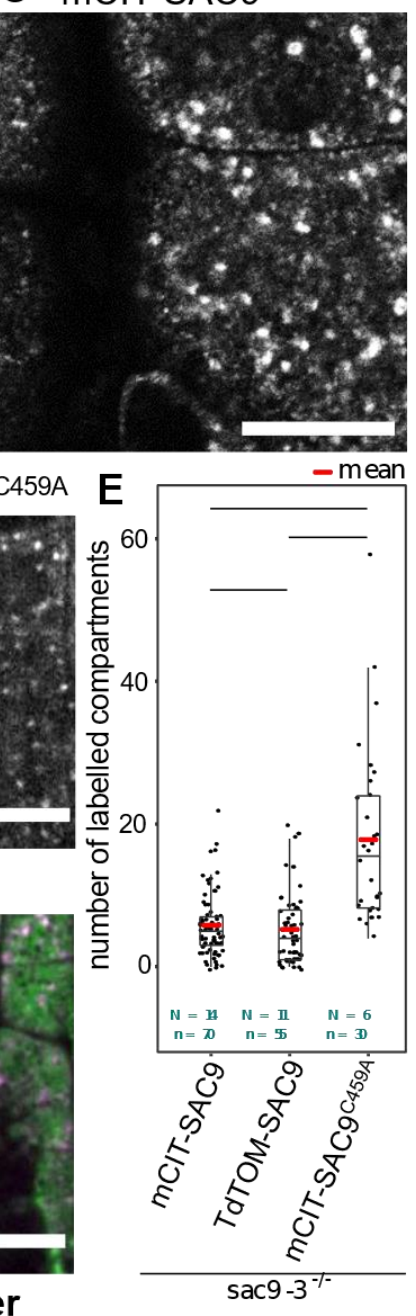

merge mCIT-SAC9C459A
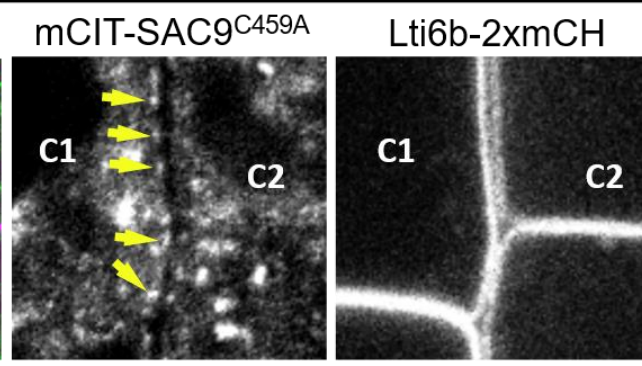

C2

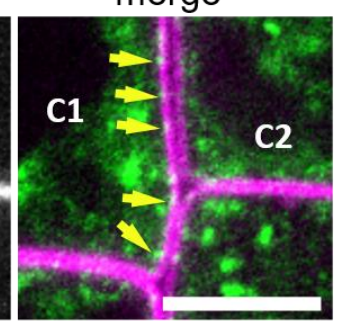

Figure 2. A, Schematic representation of two root epidermal cells (C1 and C2) imaged in this study. The blue bar represents the depth at which the imaging was performed. B, Confocal images of the subcortical part Arabidopsis root epidermal cell expressing mCIT-SAC9 under the control of SAC9 native promoter (SAC9prom). C, Confocal images of the subcortical part Arabidopsis root epidermal cell expressing mCIT-SAC9C459A under the control of $S A C 9$ native promoter (SAC9prom). D, Representative images of the fluorescent signal observe in sac9-3 $\%$ mutant expressing mCIT-SAC9, TdTOM-SAC9 and mCIT-SAC9C459A. E, Comparison of the number of labeled intracellular compartments per cell in sac $\%-3 \%$ root epidermis expressing mCIT-SAC9 and TdTOM-SAC9, mCIT-SAC9C459A. In the plot, middle horizontal bars represent the median, while the bottom and top of each box represent the 25th and 75th percentiles, respectively. At most, the whiskers extend to 1.5 times the interquartile range, excluding data beyond. For range of value under 1,5 IQR, whiskers represent the range of maximum and minimum values. F, Colocalization analysis on Ub10pro:TdTOM-SAC9 (magenta) and SAC9pro:CIT-SAC9C459A (green). G, Co-visualization of SAC9pro:CIT-SAC9C459A (green) together with the membrane localized reporter Lti6b-2xmCH (magenta) close to the basal plasma membrane of an epidermal root cell (C1). The yellow arrows indicate the intracellular compartment decorated by CIT-SAC9C459A observed at the close vicinity to the labelled plasma membrane. Scale bar: $10 \mu \mathrm{m}$ in A-F; $5 \mu \mathrm{m}$ in G (left panel) and $2 \mu \mathrm{m}$ in the close up of G (right panel). 
bioRxiv preprint doi: https://doi.org/10.1101/2021.09.10.459735; this version posted September 12, 2021. The copyright holder for this preprint (which was not certified by peer review) is the author/funder. All rights reserved. No reuse allowed without permission.

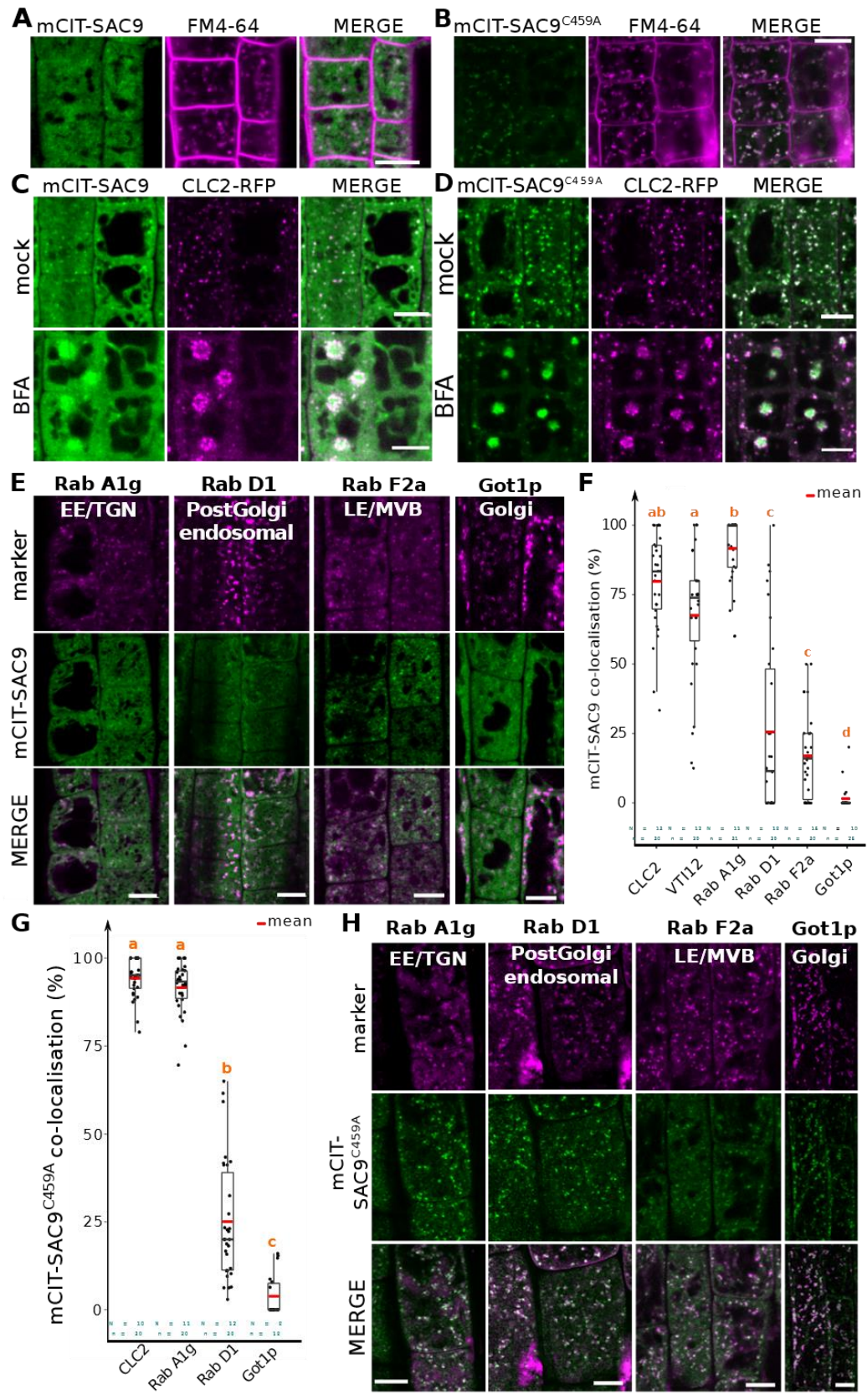

Figure 3. A, B Confocal images of $S A C 9$ pro:mCIT-SAC9 (A, green) or $S A C 9$ pro:mCIT- $S A C 9 C 459 A$ (B, green) in vivo in Arabidopsis root epidermis together with the endocytic tracer FM4-64 (magenta). Scale bar: $10 \mu \mathrm{m}$. C, D Confocal images of Arabidopsis root epidermis co-expressing SAC9pro:mCIT-SAC9 (C, green) or SAC9pro:mCIT-SAC9C459A (D, green) together with and Clathrin Light Chain 2 (CLC2) fused to RFP (UBQ10pro:CLC2-RFP; magenta). Upper panel: fluorescent signals observed in the mock treatment; Lower panel: fluorescent signals observed after $50 \mu \mathrm{M} 60 \mathrm{~min}$ BFA treatment. Scale bars: $10 \mu \mathrm{m}$. E, Confocal images of Arabidopsis root epidermis co-expressing SAC9pro:mCIT-SAC9 (green) and TGN markers $m C H$-RabA1g, $m C H$-RabD1 (magenta), the late endosome/pre--vacuolar compartment (LE/MVB) marker $m \mathrm{CH}$-RabF2a/Rha1 (magenta) and the Golgi marker $m \mathrm{CH}$-Got1p (magenta). Scale bars: $10 \mu \mathrm{m}$. F, Quantification of the percentage of colocalization between mCIT-SAC9 and a given endosomal compartment marker per cell. G, Quantification of the percentage of colocalization between mCIT-SAC9C459A and a given endosomal compartment marker. Similar letters correspond to markers with non-significantly different percentages of colocalization with mCIT-SAC9C459A (one-way ANOVA and post hoc Tuckey HSD pairwise test with a $95 \%$ confidence level). In the plots, middle horizontal bars represent the median, while the bottom and top of each box represent the 25th and 75th percentiles, respectively. At most, the whiskers extend to 1.5 times the interquartile range, excluding data beyond. For range of value under 1,5 IQR, whiskers represent the range of maximum and minimum values. E, Confocal images of Arabidopsis root epidermis co-expressing SAC9pro:mCIT-SAC9C459A (green) and TGN markers $m C H$-RabA1g, $m C H$-RabD1 (magenta), the late endosome/pre-vacuolar compartment (LE/MVB) marker $m \mathrm{CH}$-RabF2a/Rha1 (magenta) and the Golgi marker $m \mathrm{CH}-\mathrm{Got1} p$ (magenta). Scale bars: $10 \mu \mathrm{m}$. 
bioRxiv preprint doi: https://doi.org/10.1101/2021.09.10.459735; this version posted September 12, 2021. The copyright holder for this preprint (which was not certified by peer review) is the author/funder. All rights reserved. No reuse allowed without permission.
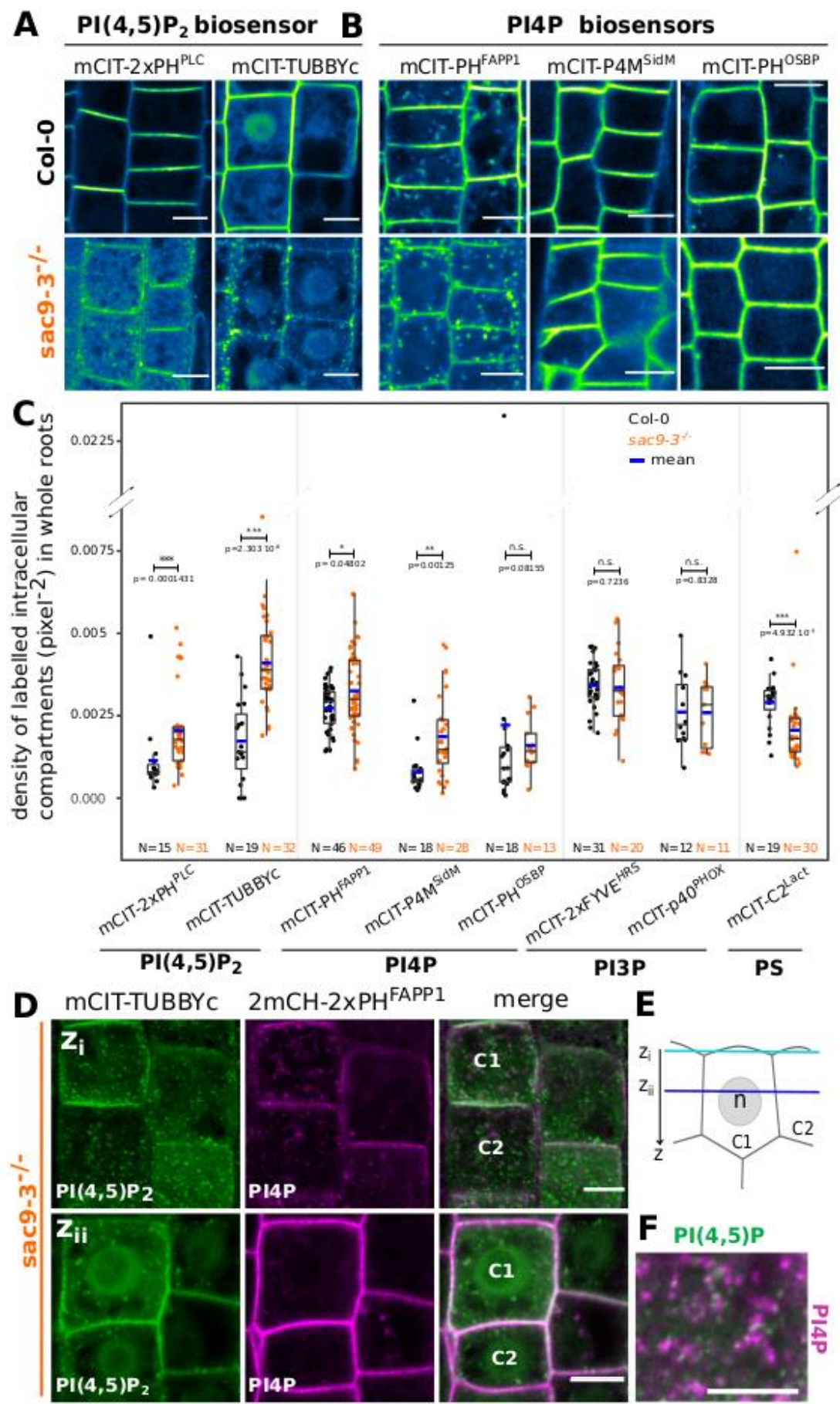

Figure 4. A, Confocal images of Arabidopsis root epidermis expressing mCIT-tagged PI(4,5) $\mathrm{P}_{2}$ sensors in WT (Col-0) and sac9-31- genetic backgrounds. B, Confocal images of Arabidopsis root epidermis expressing mCIT-tagged PI4P sensors in Wild-type (Col0 ) and sac9-3\% genetic backgrounds. Fluorescence intensity is color-coded (green fire blue scale). C, Quantification of density of labelled intracellular compartments ( pixel- $^{-2}$ ) in whole roots epidermis expressing mCIT-tagged lipid sensors in wild-type (Col-0) and sac9-3\%. Non-parametric Wilcoxon rank sum tests with Bonferroni correction. In the plots, middle horizontal bars represent the median, while the bottom and top of each box represent the 25th and 75th percentiles, respectively. At most, the whiskers extend to 1.5 times the interquartile range, excluding data beyond. For range of value under 1,5 IQR, whiskers represent the range of maximum and minimum values. Details for statistical analysis can be found in the Methods section and supplementary Tables. D, Confocal images of sac9-3\% Arabidopsis root epidermal cell (C1 and C2) expressing $m C I T-T U B B Y c$ (green) and 2xmCH-PHFAPP1 (magenta) at their cortex (upper panel, $\mathrm{Zi}$ ) and at their center (bottom panel, Zii). E, Schematic representation of two root epidermal cells (C1 and C2) imaged in D. The blue bars represent the depth at which the imaging was performed. F, close up (form a different cell) of the distribution of the intracellular compartments in sac9-3\% epidermal cell labelled by mCIT-TUBBYc (green) and $2 \mathrm{xmCH}-$ PHFAPP1 (magenta). Scale bar: $10 \mu \mathrm{m}$ in A-D, $5 \mu \mathrm{m}$ in F. 
bioRxiv preprint doi: https://doi.org/10.1101/2021.09 10.459735; this version posted September 12, 2021. The copyright holder for this preprint (which was not certified by peer review) is the author/funder. All rights reserved. No reuse allowed without permission.

A

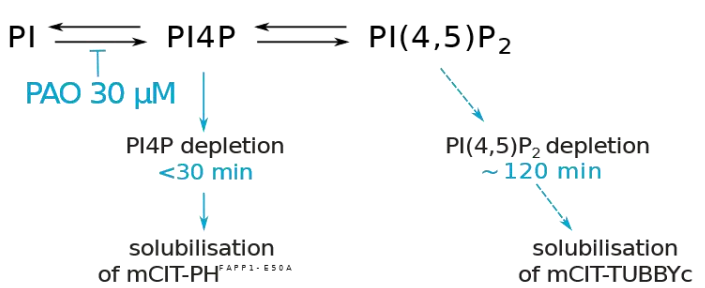

B

Col-0

C $\operatorname{sac} 9-3^{-/-}$

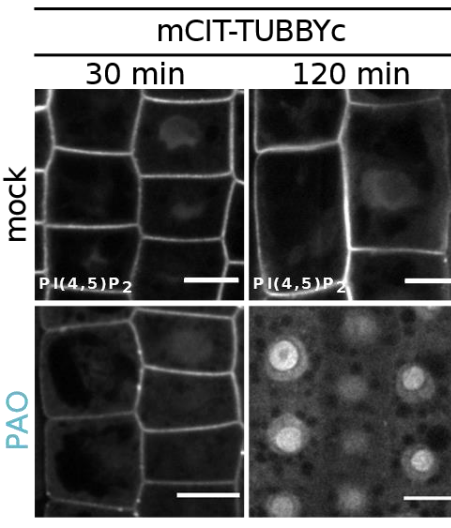

mCIT-TUBBYC

Figure 5. A, Schematic representation of the mode of action of the PAO on the PI4P and PI(4,5) $\mathrm{P}_{2}$ metabolism based on previously published work (Doumane et al. 2020; Platre et al. 2018). B, Confocal images of WT root epidermal cells expressing mCIT-TUBBYc PI $(4,5) \mathrm{P}_{2}$ biosensor that underwent mock, or $30 \mu \mathrm{M}$ PAO treatments for 30- or 120- min. C, Confocal images of sac9-3\% root epidermal cells expressing mCIT-TUBBYc PI(4,5) $\mathrm{P}_{2}$ biosensor that underwent mock, or $30 \mu \mathrm{M}$ PAO treatments for 30- or 120- min. D, Quantification of the number of mCIT-TUBBYc labeled intracellular compartments per cell in sac $9-3 \%$ following mock, or $30 \mu \mathrm{M}$ PAO treatments for 30- or 120- min. Generalized linear mixed effect model (Poisson family) to account for root as a random factor, and two sided post hoc lsmeans pair wise test with a $95 \%$ confidence level. In the plot, middle horizontal bars represent the median, while the bottom and top of each box represent the 25th and 75th percentiles, respectively. At most, the whiskers extend to 1.5 times the interquartile range, excluding data beyond. For range of value under $1,5 \mathrm{IQR}$, whiskers represent the range of maximum and minimum values. All statistical tests were two-sided. E, Confocal images of sac9-3\% root epidermal cells expressing mCIT-PHFAPP1-E50A PI4P biosensor that underwent mock or $30 \mu \mathrm{M}$ PAO treatments for 30- or 120min. Scale bar: $10 \mu \mathrm{m}$. 
bioRxiv preprint doi: https://doi org/10.1101/2021.09.10.459735; this version posted September 12, 2021. The copyright holder for this preprint (which was not certified by peer review) is the author/funder. All rights reserved. No reuse allowed without permission.
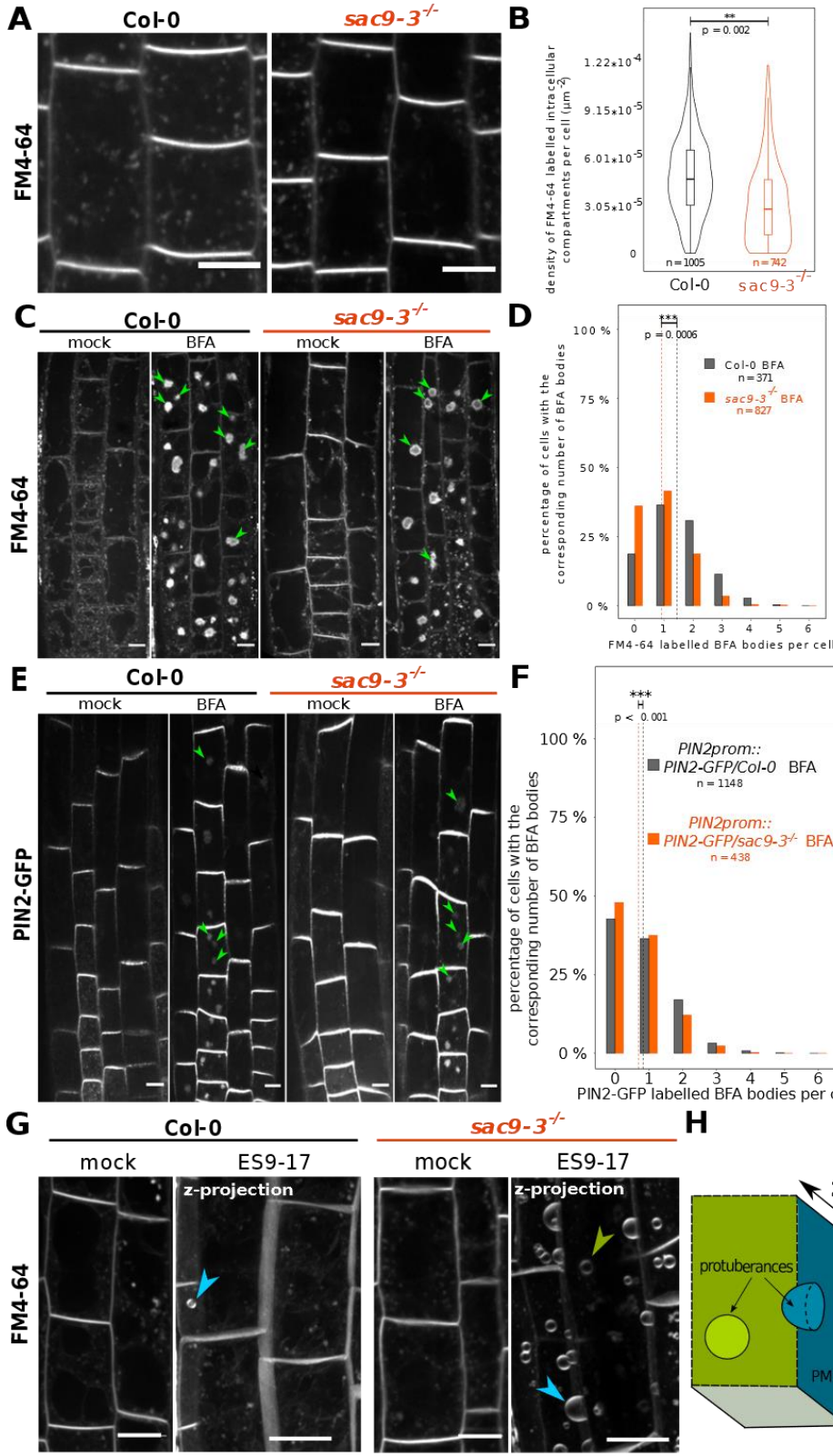
$\mathbf{H}$

Figure 6. A, Representative images of Col-0 and sac9-3\% seedlings treated for 30 min with FM4-64, which is endocytosed and labels endocytic intracellular compartments. Scale bar: $10 \mu \mathrm{m}$. B, Quantification from the experiment showed in (A). Violin and box plots quantifying the number of FM4-64 labeled intracellular compartments in Col-0 and sac9-3\%. C, Representative images of root epidermis following BFA and FM4-64 treatment of Col-0 and sac9-3\% seedlings. Examples of FM4-64 labeled BFA bodies are pointed out (green arrowheads). D, Quantification from the experiment showed in (C). For Col-0 and sac $9-3 \%$, the proportion (\%) of cells containing from none to six BFA bodies is displayed. Dotted line: means. E, Representative images following BFA treatment of PIN2-GFP/WT and PIN2-GFP/sac9-3\% seedlings. Examples of PIN2-GFP labeled BFA bodies are pointed out (green arrowheads). Scale bars: $10 \mu \mathrm{m}$. F, Quantification from the experiment showed in (E). For PIN2-GFP/WT and PIN2$\mathrm{GFP} /$ sac9-3\%, the proportion (\%) of cells containing from none to six BFA bodies is displayed. Dotted line: means. G, Oversensitivity of sac9-3\% to prolonged inhibition of endocytosis. Seedlings were treated 180 min with $30 \mu \mathrm{M}$ ES9-17 or DMSO (mock), FM4-64 being added after $30 \mathrm{~min}$ (150 min of exposure). The picture showed after the ES9-17 treatment are the results of the projection of a z-stack. H, ES9-17 treatments led to dome-shaped plasma membrane invagination. blue arrowheads: invaginations with an obvious connection to the plasma membrane; green arrowheads: invaginations without a clear connection to the plasma membrane (often connected to medullar plasma membrane). Scale bars: $10 \mu \mathrm{m}$. 
bioRxiv preprint doi: https://doi.org/10.1101/2021.09.10.459735; this version posted September 12, 2021. The copyright holder for this preprint (which was not certified by peer review) is the author/funder. All rights reserved. No reuse allowed without permission.
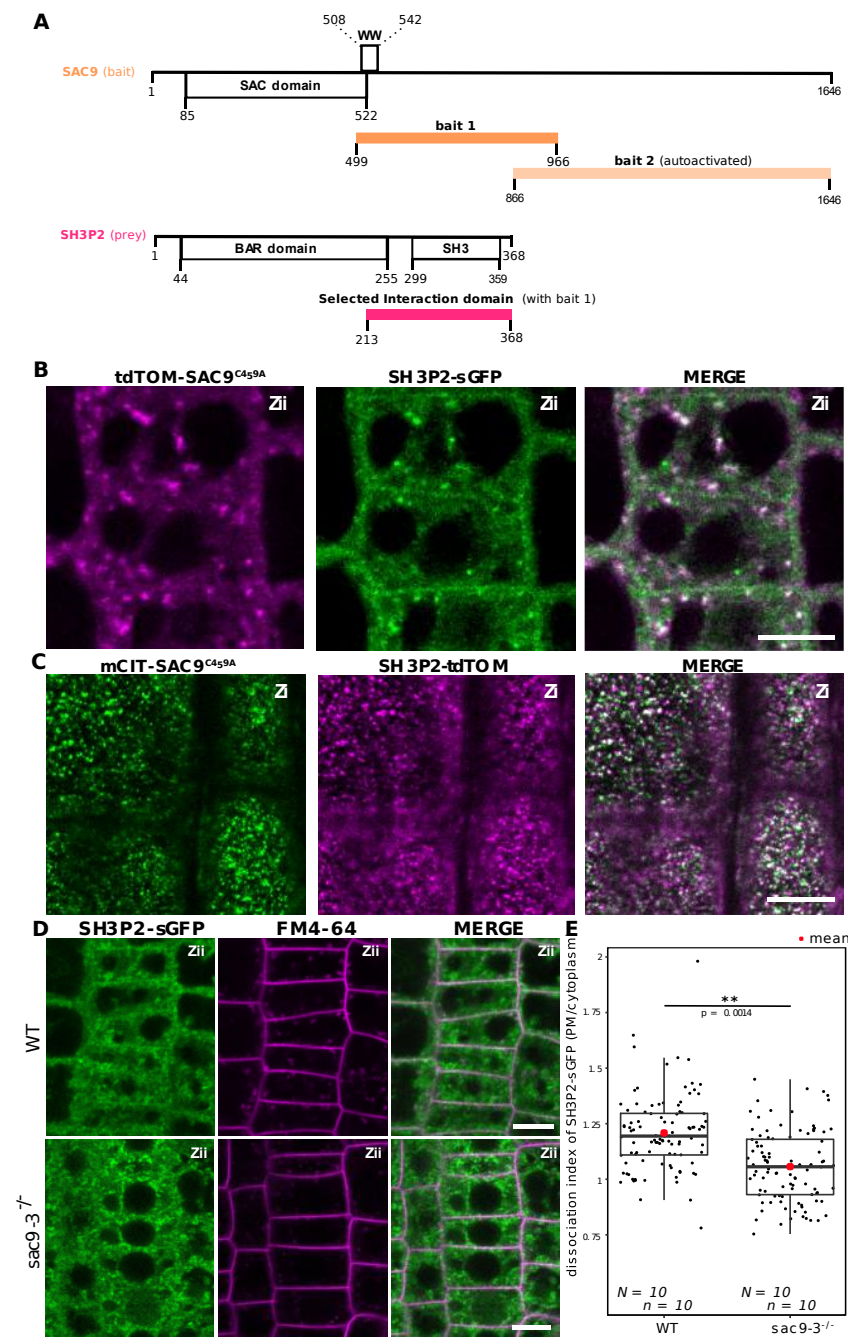

Figure 7. A, Schematic representation of the yeast two-hybrid screen using SAC9 as a bait, where SH3P2 was found as a protein partner. The selected interaction domain (interacting with bait 1) corresponds to the amino acid sequence shared by all the eleven prey fragments matching the same reference protein. Note that one other fragment of SAC9 was attended to be screened for interacting proteins (bait 2), but the construct was autoactivate in yeast. For design purpose, the scale between SAC9 and SH3P2 was not respected. B, Representatives images of the in vivo colocalization analysis between tdTOM-SAC9C459A (magenta) and SH3P2-sGFP (green) in a distal region from the plasma membrane. Scale $=5 \mu \mathrm{m}$. C, Representatives images of the in vivo colocalization analysis between mCITSAC9 ${ }^{459 A}$ (green) and SH3P2-tdTOM (magenta) near the plasma membrane. Scale $=5 \mu \mathrm{m}$. The light blue line (zi) corresponds to the in vivo imaging near the plasma membrane observed by confocal imaging and the dark blue line (zii) corresponds to the in vivo imaging in a distal region from the plasma membrane. (See Figure 4E for details) $\mathbf{D}$, Representatives images of the SH3P2-sGFP localization (green) in WT and sac9-3 mutant in which the plasma membrane was labelled using FM4-64 (magenta). E, Double blinded quantification of the dissociation index of SH3P2-sGFP in WT and sac9-3 mutant in which the plasma membrane was labelled using FM4-64. Linear mixed model (lmer in lme4) then type II Wald chisquare test: Chisq $=10.152, \mathrm{df}=1, \mathrm{p}=0.001441$. In the plot, middle horizontal bars represent the median, while the bottom and top of each box represent the 25th and 75th percentiles, respectively. At most, the whiskers extend to 1.5 times the interquartile range, excluding data beyond. For range of value under 1,5 IQR, whiskers represent the range of maximum and minimum values. 
bioRxiv preprint doi: https://doi org/10.1101/2021.09.10.459735; this version posted September 12, 2021. The copyright holder for this preprint (which was not certified by peer review) is the author/funder. All rights reserved. No reuse allowed without permission.
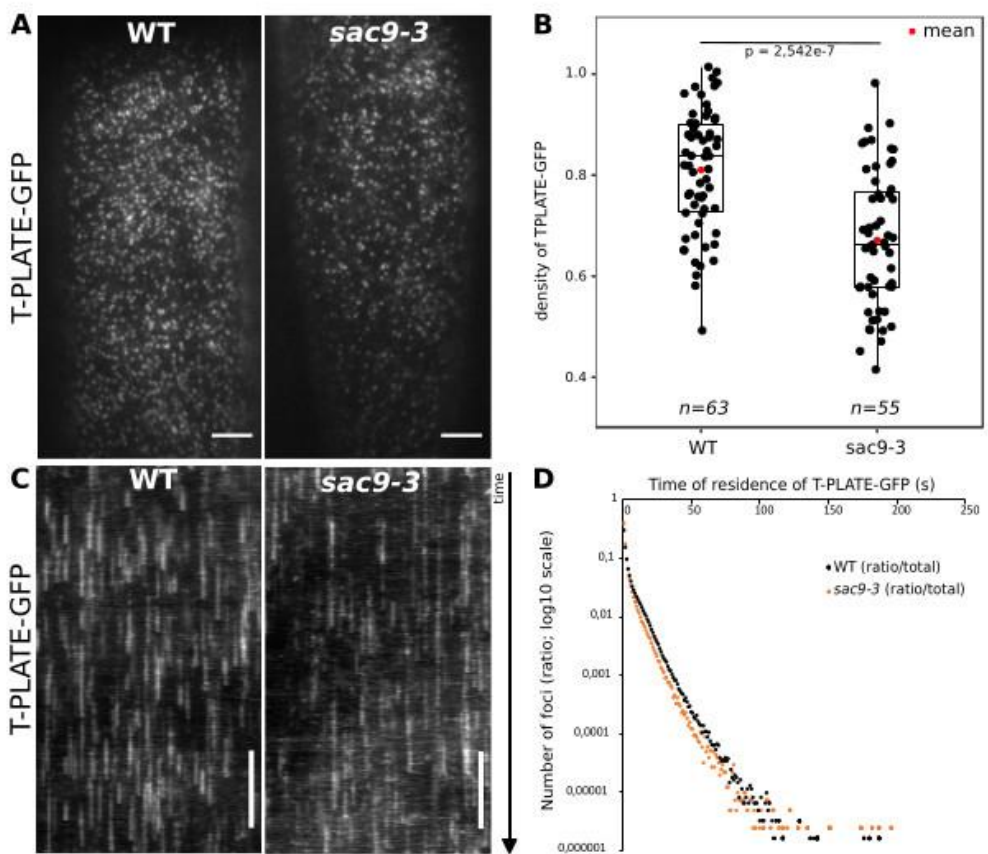

Figure 8. A, Representatives images of the TPLATE-GFP localization in WT and sac $9-3$ mutant at the plasma membrane observed by TIRF microscopy in etiolated hypocotyl. Scale $=5 \mu \mathrm{m}$. B, Quantification of the density at the plasma membrane of SH3P2sGFP in WT and sac9-3 mutant observed by TIRF microscopy. Only one of the three replicates is represented. In the plots, middle horizontal bars represent the median, while the bottom and top of each box represent the 25th and 75th percentiles, respectively. At most, the whiskers extend to 1.5 times the interquartile range, excluding data beyond. For range of value under 1,5 IQR, whiskers represent the range of maximum and minimum values. $\mathbf{C}$, Representatives kymograph of the TPLATE-GFP dynamics at the plasma membrane in W'T and sac9-3 mutant observed by TIRF microscopy in etiolated hypocotyl over 5 min, scale $=60 \mathrm{~s}$. D, Quantification of the time of residency at the plasma membrane of TPLATE-GFP in WT (black dots) and sac9-3 mutant (oranges dots) observed by TIRF microscopy in a time lapses acquired during 300 time-points for 300 s (acquisition time $500 \mathrm{~ms}$ ). The data are represented in a $\log 10$ scale for the residency time at the PM, and the time scale is represented in sec.

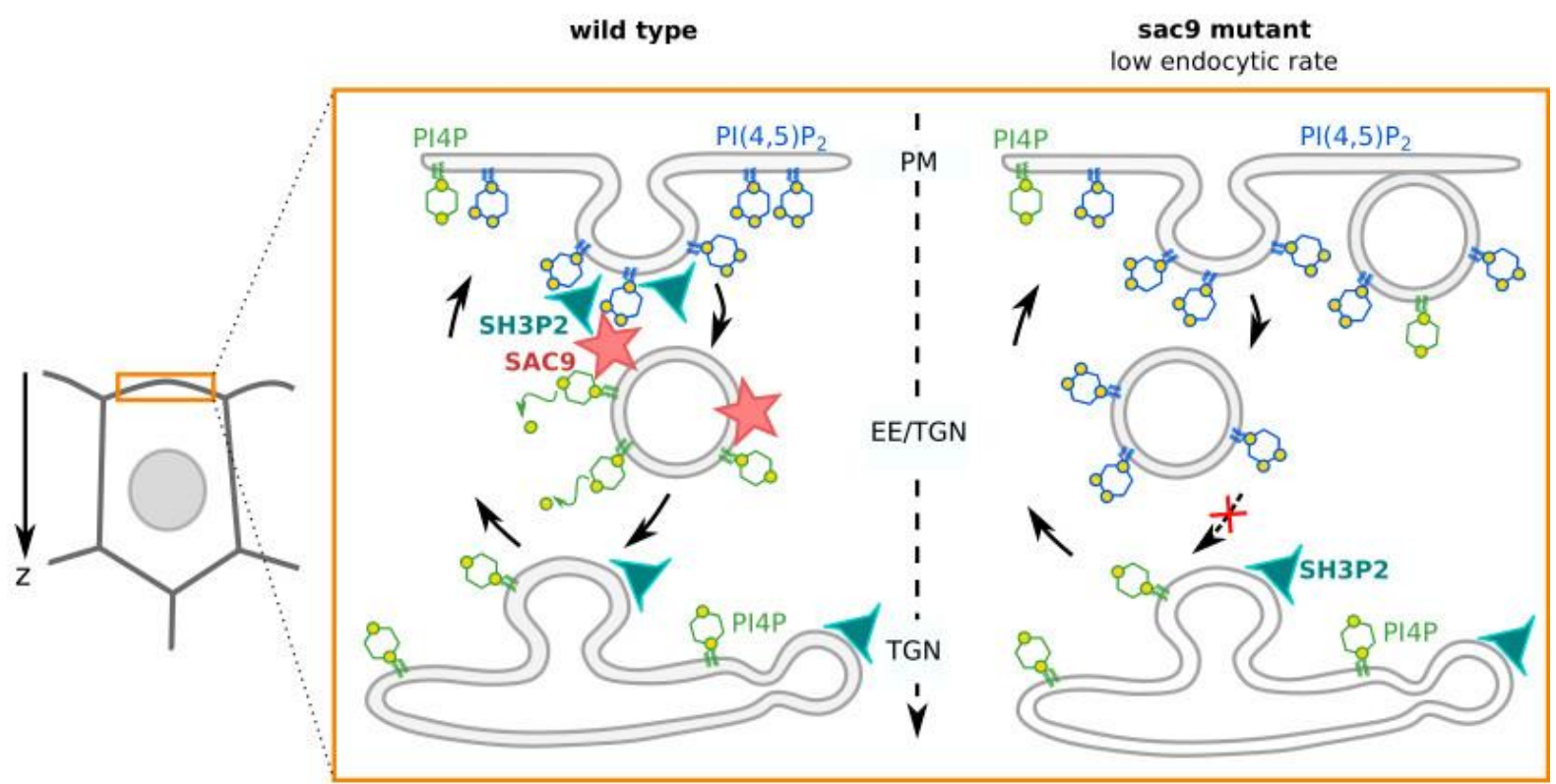

Figure 9. Model for the mode of action of SAC9 in regulating the $\mathrm{PI}(4,5) \mathrm{P}_{2}$ homeostasis at the close vicinity with the plasma membrane. In wild type plants, SAC9 restricts the localization of $\mathrm{PI}(4,5) \mathrm{P}_{2}$ at the plasma membrane allowing endocytic processes to occur. In the absence of $\mathrm{SAC}$, endocytosis $\mathrm{PI}(4,5) \mathrm{P}_{2}$ accumulates in atypical endomembrane compartments that are no longer able to fuse with the TGN because of their abnormal anionic lipid signature. SAC9 interacts with SH3P2 close to the plasma membrane. The defects in $\mathrm{PI}(4,5) \mathrm{P}_{2}$ patterning in absence of SAC9 leads to decreasing of the endocytic rate and the formation of membrane protuberances in contact with the plasma membrane. 
Supplemental Fig.1. A, Western blot analysis. Leaf lysates from Col-0, sac9-3\%, SAC9pro:mCIT-SAC9/sac9-3\%, SAC9pro:mCIT$S A C 94459 /$ sac9-3\%- were immunoprecipitated with an anti-GFP antibody, run on an SDS-PAGE and immunoblotted with antiGFP primary antibody. B, Confocal imaging of mCIT-SAC9 (green) together with the nuclear marker CENH3-RFP (magenta).
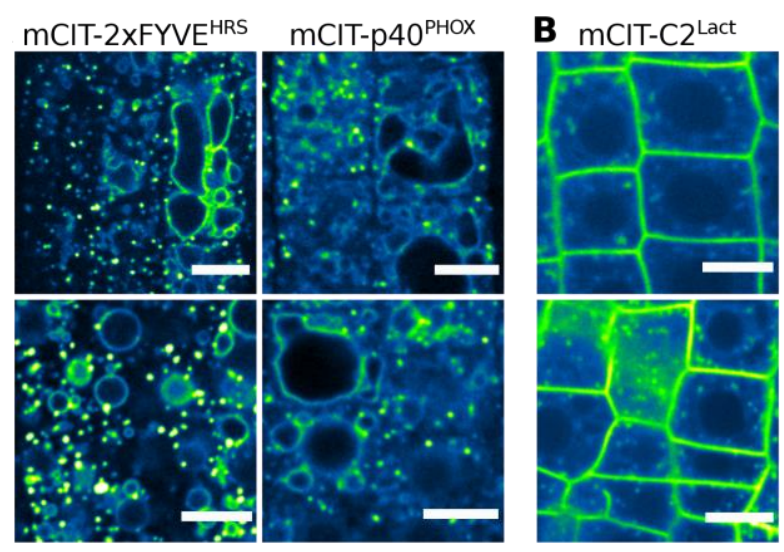

Supplemental Fig.2. A, Representative confocal images of Arabidopsis root epidermis expressing mCIT-tagged lipid sensors for PI3P in wild-type (Col-0) and sac9-3\% genetic backgrounds. B, Confocal images of Arabidopsis root epidermis expressing mCITtagged lipid sensors for phosphatidylserine (PS) in wild-type (Col-0) and sac $9-3 \%$ genetic backgrounds. Fluorescence intensity is color-coded (green fire blue scale). Scale bars: $10 \mu \mathrm{m}$. 
bioRxiv preprint doi: https://doi.org/10.1101/2021.09 10.459735; this version posted September 12, 2021. The copyright holder for this preprint (which was not certified by peer review) is the author/funder. All rights reserved. No reuse allowed without permission.
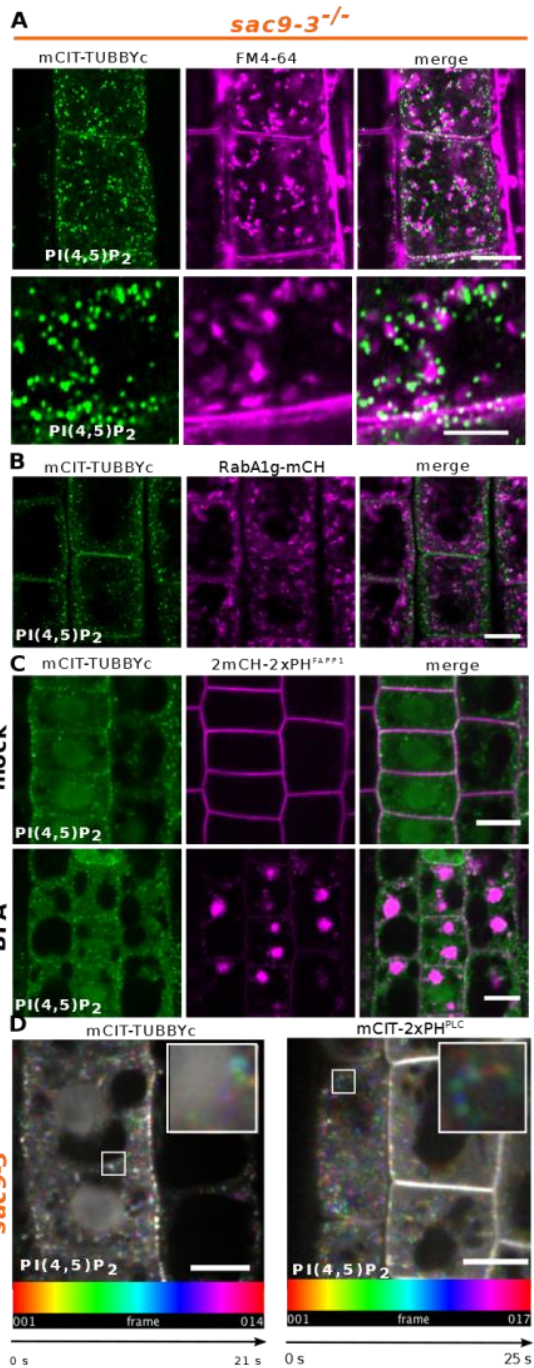

Supplemental Fig.3. A, Confocal images of sac9-3\% Arabidopsis root epidermis expressing mCIT-TUBBYc (green) and in vivo stained with FM4-64 endocytic tracer (magenta). B, Confocal images of sac $\%-3 \%$ root epidermal cells co-expressing mCIT-TUBBYc (green) and the TGN marker RabA1g-mCH (magenta). C, Confocal images of sac9-3\% root epidermal cells co-expressing mCITTUBBYc (green) and 2xmCH-PHFAPP1 (magenta). Upper panel: fluorescent signals observed in the mock treatment; lower panel: fluorescent signal observed after $50 \mu \mathrm{M} 60$ min BFA treatment. D, Temporal-color coded XY 2D image of mCIT-2xPH ${ }^{\text {PLC }}$ and mCIT-TUBBYc in sac9-3\% root epidermis (Fiji Spectrum Temporal-color code). Scale bar: $10 \mu \mathrm{m}$. 


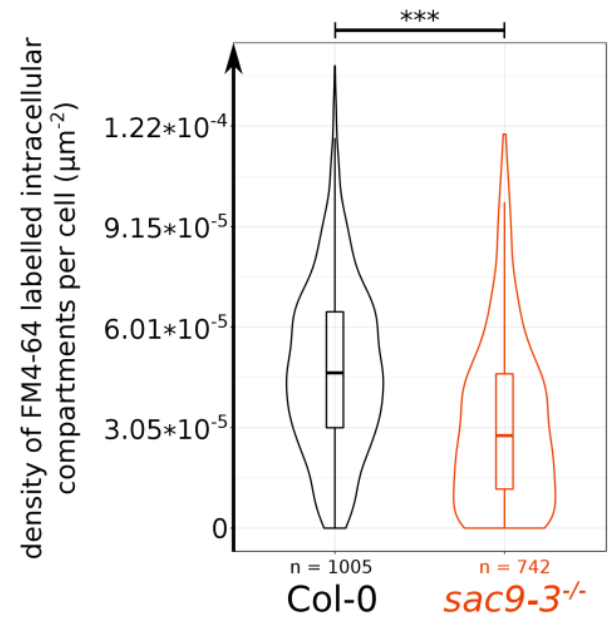

765 Supplemental Fig.4. Quantification from the FM4-64 uptake assay. Violin and box plots quantifying the density of FM4-64 labeled intracellular compartments in Col-0 and $s a c 9-3 \%$. N: number of cells. Linear mixed model (Poisson family) to account for root as a random factor. ${ }^{* * *}$ p-value $<0.0005$.

Supplemental Movie 1. Time-lapse imaging of mCIT-SAC9 using spinning disk confocal microscope

Supplemental Movie 2. Time-lapse imaging of mCIT-2xPH ${ }^{\text {PLC }}$ in sac9 mutant (1 sec per frame) using spinning disk confocal microscope. 


\section{REFERENCES}

Abad U, Sassi M, Traas J (2017) Flower development: from morphodynamics to morphomechanics. Philosophical transactions of the Royal Society of London Series B, Biological sciences 372 (1720). doi:10.1098/rstb.2015.0545

Adamowski M, Narasimhan M, Kania U, Glanc M, De Jaeger G, Friml J (2018) A Functional Study of AUXILIN-LIKE1 and 2, Two Putative Clathrin Uncoating Factors in Arabidopsis. The Plant cell 30 (3):700-716. doi:10.1105/tpc.17.00785

Ahn G, Kim H, Kim DH, Hanh H, Yoon Y, Singaram I, Wijesinghe KJ, Johnson KA, Zhuang X, Liang Z, Stahelin RV, Jiang L, Cho W, Kang BH, Hwang I (2017) SH3 DomainContaining Protein 2 Plays a Crucial Role at the Step of Membrane Tubulation during Cell Plate Formation. The Plant cell 29 (6):1388-1405. doi:10.1105/tpc.17.00108

Armengot L, Marquès-Bueno MM, Jaillais $Y$ (2016) Regulation of polar auxin transport by protein and lipid kinases. Journal of experimental botany 67 (14):4015-4037

Balla T (2013) Phosphoinositides: tiny lipids with giant impact on cell regulation. Physiol Rev 93 (3):1019-1137. doi:10.1152/physrev.00028.2012

Bates D, Mächler M, Bolker B, Walker S (2014) Fitting linear mixed-effects models using Ime4. arXiv preprint arXiv:14065823

Ben El Kadhi K, Roubinet C, Solinet S, Emery G, Carreno S (2011) The inositol 5-phosphatase dOCRL controls $\mathrm{Pl}(4,5) \mathrm{P} 2$ homeostasis and is necessary for cytokinesis. Current biology : CB 21 (12):1074-1079. doi:10.1016/j.cub.2011.05.030

Carim SC, Ben El Kadhi K, Yan G, Sweeney ST, Hickson GR, Carreno S, Lowe M (2019) IPIP27 Coordinates Ptdlns(4,5)P2 Homeostasis for Successful Cytokinesis. Current biology : CB 29 (5):775-789 e777. doi:10.1016/j.cub.2019.01.043

Carland F, Nelson T (2009) CVP2- and CVL1-mediated phosphoinositide signaling as a regulator of the ARF GAP SFC/VAN3 in establishment of foliar vein patterns. The Plant journal : for cell and molecular biology 59 (6):895-907. doi:10.1111/j.1365313X.2009.03920.x

Carland FM, Nelson T (2004) Cotyledon vascular pattern2-mediated inositol $(1,4,5)$ triphosphate signal transduction is essential for closed venation patterns of Arabidopsis foliar organs. The Plant cell 16 (5):1263-1275. doi:10.1105/tpc.021030

Cauvin C, Rosendale M, Gupta-Rossi N, Rocancourt M, Larraufie P, Salomon R, Perrais D, Echard A (2016) Rab35 GTPase Triggers Switch-like Recruitment of the Lowe Syndrome Lipid Phosphatase OCRL on Newborn Endosomes. Current biology : CB 26 (1):120-128. doi:10.1016/j.cub.2015.11.040

De Matteis MA, Staiano L, Emma F, Devuyst O (2017) The 5-phosphatase OCRL in Lowe syndrome and Dent disease 2. Nature Reviews Nephrology 13 (8):455-470. doi:10.1038/nrneph.2017.83

Dejonghe W, Sharma I, Denoo B, De Munck S, Lu Q, Mishev K, Bulut H, Mylle E, De Rycke R, Vasileva M, Savatin DV, Nerinckx W, Staes A, Drozdzecki A, Audenaert D, Yperman K, Madder A, Friml J, Van Damme D, Gevaert K, Haucke V, Savvides SN, Winne J, Russinova E (2019) Disruption of endocytosis through chemical inhibition of clathrin heavy chain function. Nat Chem Biol 15 (6):641-649. doi:10.1038/s41589-0190262-1

Del Signore SJ, Biber SA, Lehmann KS, Heimler SR, Rosenfeld BH, Eskin TL, Sweeney ST, Rodal AA (2017) dOCRL maintains immune cell quiescence by regulating endosomal traffic. PLoS Genet 13 (10):e1007052. doi:10.1371/journal.pgen.1007052

Dettmer J, Hong-Hermesdorf A, Stierhof YD, Schumacher K (2006) Vacuolar H+-ATPase activity is required for endocytic and secretory trafficking in Arabidopsis. The Plant cell 18 (3):715-730. doi:10.1105/tpc.105.037978

Doumane M, Colin L, Lebecq A, Fangain A, Bareille J, Hamant O, Belkhadir Y, Jaillais Y, Caillaud M-C (2020) iDePP: a genetically encoded system for the inducible depletion of $\mathrm{PI}(4,5) \mathrm{P} 2$ in Arabidopsis thaliana. bioRxiv 
Doumane M, Lebecq A, Colin L, Fangain A, Stevens FD, Bareille J, Hamant O, Belkhadir Y, Munnik T, Jaillais $\mathrm{Y}$, Caillaud MC (2021) Inducible depletion of PI(4,5)P2 by the synthetic iDePP system in Arabidopsis. Nat Plants 7 (5):587-597. doi:10.1038/s41477021-00907-z

Flanagan CA, Schnieders EA, Emerick AW, Kunisawa R, Admon A, Thorner J (1993) Phosphatidylinositol 4-kinase: gene structure and requirement for yeast cell viability. Science 262 (5138):1444-1448. doi:10.1126/science.8248783

Fox J, Weisberg S (2011) The car package contains functions and data sets associated with the book an $\mathrm{R}$ companion to applied regression. R-Project.

Geldner N, Denervaud-Tendon V, Hyman DL, Mayer U, Stierhof YD, Chory J (2009) Rapid, combinatorial analysis of membrane compartments in intact plants with a multicolor marker set. The Plant journal : for cell and molecular biology 59 (1):169-178. doi:10.1111/j.1365-313X.2009.03851.x

Golani Y, Kaye Y, Gilhar O, Ercetin M, Gillaspy G, Levine A (2013) Inositol polyphosphate phosphatidylinositol 5-phosphatase9 (At5ptase9) controls plant salt tolerance by regulating endocytosis. Molecular plant 6 (6):1781-1794. doi:10.1093/mp/sst072

Gujas B, Cruz TMD, Kastanaki E, Vermeer JEM, Munnik T, Rodriguez-Villalon A (2017) Perturbing phosphoinositide homeostasis oppositely affects vascular differentiation in $\begin{array}{llll}\text { Arabidopsis thaliana roots. Development } 144 & (19): 3578-3589 .\end{array}$ doi:10.1242/dev.155788

Guo S, Stolz LE, Lemrow SM, York JD (1999) SAC1-like domains of yeast SAC1, INP52, and INP53 and of human synaptojanin encode polyphosphoinositide phosphatases. The Journal of biological chemistry 274 (19):12990-12995

Gurung R, Tan A, Ooms LM, McGrath MJ, Huysmans RD, Munday AD, Prescott M, Whisstock JC, Mitchell CA (2003) Identification of a novel domain in two mammalian inositolpolyphosphate 5-phosphatases that mediates membrane ruffle localization. The inositol 5-phosphatase skip localizes to the endoplasmic reticulum and translocates to membrane ruffles following epidermal growth factor stimulation. The Journal of biological chemistry 278 (13):11376-11385. doi:10.1074/jbc.M209991200

He K, Marsland lii R, Upadhyayula S, Song E, Dang S, Capraro BR, Wang W, Skillern W, Gaudin R, Ma M, Kirchhausen T (2017) Dynamics of phosphoinositide conversion in clathrin-mediated endocytic traffic. Nature 552 (7685):410-414. doi:10.1038/nature25146

Hothorn T, Bretz F, Westfall P, Heiberger RM (2008) Multcomp: simultaneous inference for general linear hypotheses. $R$ package version:1.0-3

Hughes WE, Woscholski R, Cooke FT, Patrick RS, Dove SK, McDonald NQ, Parker PJ (2000) SAC1 encodes a regulated lipid phosphoinositide phosphatase, defects in which can be suppressed by the homologous Inp52p and Inp53p phosphatases. The Journal of biological chemistry 275 (2):801-808

Ischebeck T, Werner S, Krishnamoorthy P, Lerche J, Meijon M, Stenzel I, Lofke C, Wiessner T, Im YJ, Perera IY, Iven T, Feussner I, Busch W, Boss WF, Teichmann T, Hause B, Persson S, Heilmann I (2013) Phosphatidylinositol 4,5-bisphosphate influences PIN polarization by controlling clathrin-mediated membrane trafficking in Arabidopsis. The Plant cell 25 (12):4894-4911. doi:10.1105/tpc.113.116582

Karimi M, Depicker A, Hilson P (2007) Recombinational cloning with plant gateway vectors. Plant physiology 145 (4):1144-1154. doi:10.1104/pp.107.106989

Lenth R, Lenth MR (2018) Package 'Ismeans'. The American Statistician 34 (4):216-221

Mei Y, Jia WJ, Chu YJ, Xue HW (2012) Arabidopsis phosphatidylinositol monophosphate 5kinase 2 is involved in root gravitropism through regulation of polar auxin transport by affecting the cycling of PIN proteins. Cell research 22 (3):581-597. doi:10.1038/cr.2011.150

Mochizuki Y, Takenawa T (1999) Novel inositol polyphosphate 5-phosphatase localizes at membrane ruffles. The Journal of biological chemistry 274 (51):36790-36795. doi:10.1074/jbc.274.51.36790 
Nagel MK, Kalinowska K, Vogel K, Reynolds GD, Wu Z, Anzenberger F, Ichikawa M, Tsutsumi C, Sato MH, Kuster B, Bednarek SY, Isono E (2017) Arabidopsis SH3P2 is an ubiquitin-binding protein that functions together with ESCRT-I and the deubiquitylating enzyme AMSH3. Proceedings of the National Academy of Sciences of the United States of America 114 (34):E7197-E7204. doi:10.1073/pnas.1710866114

Nandez R, Balkin DM, Messa M, Liang L, Paradise S, Czapla H, Hein MY, Duncan JS, Mann $\mathrm{M}$, De Camilli $\mathrm{P}$ (2014) A role of OCRL in clathrin-coated pit dynamics and uncoating revealed by studies of Lowe syndrome cells. Elife 3:e02975. doi:10.7554/eLife.02975

Narasimhan M, Johnson A, Prizak R, Kaufmann WA, Tan S, Casillas-Perez B, Friml J (2020) Evolutionarily unique mechanistic framework of clathrin-mediated endocytosis in plants. Elife 9. doi:10.7554/eLife.52067

Noack L, Bayle V, Armengot L, Rozier F, Mamode-Cassim A, Stevens F, Caillaud M, Munnik $\mathrm{T}$, Mongrand S, Jaillais $\mathrm{Y}$ (2020) A nanodomain anchored-scaffolding complex is required for PI4Ka function and localization in plants. bioRxiv:2020.2012.2008.415711. doi:10.1101/2020.12.08.415711

Noack LC, Jaillais Y (2017) Precision targeting by phosphoinositides: how Pls direct endomembrane trafficking in plants. Current opinion in plant biology 40:22-33. doi:10.1016/j.pbi.2017.06.017

Noack LC, Jaillais Y (2020) Functions of Anionic Lipids in Plants. Annual review of plant biology 71:71-102. doi:10.1146/annurev-arplant-081519-035910

Novakova P, Hirsch S, Feraru E, Tejos R, van Wijk R, Viaene T, Heilmann M, Lerche J, De Rycke R, Feraru MI, Grones P, Van Montagu M, Heilmann I, Munnik T, Friml J (2014) SAC phosphoinositide phosphatases at the tonoplast mediate vacuolar function in Arabidopsis. Proceedings of the National Academy of Sciences of the United States of America 111 (7):2818-2823. doi:10.1073/pnas.1324264111

Paez Valencia J, Goodman K, Otegui MS (2016) Endocytosis and Endosomal Trafficking in Plants. Annual review of plant biology 67:309-335. doi:10.1146/annurev-arplant043015-112242

Pirruccello M, Nandez R, Idevall-Hagren O, Alcazar-Roman A, Abriola L, Berwick SA, Lucast L, Morel D, De Camilli P (2014) Identification of inhibitors of inositol 5-phosphatases through multiple screening strategies. ACS Chem Biol 9 (6):1359-1368. doi:10.1021/cb500161z

Platre MP, Jaillais Y (2016) Guidelines for the Use of Protein Domains in Acidic Phospholipid Imaging. Methods in molecular biology 1376:175-194. doi:10.1007/978-1-4939-3170$5 \_15$

Platre MP, Noack LC, Doumane M, Bayle V, Simon MLA, Maneta-Peyret L, Fouillen L, Stanislas T, Armengot L, Pejchar P, Caillaud MC, Potocky M, Copic A, Moreau P, Jaillais Y (2018) A Combinatorial Lipid Code Shapes the Electrostatic Landscape of Plant Endomembranes. Developmental cell 45 (4):465-480 e411. doi:10.1016/j.devcel.2018.04.011

Posor Y, Eichhorn-Gruenig M, Puchkov D, Schöneberg J, Ullrich A, Lampe A, Müller R, Zarbakhsh S, Gulluni F, Hirsch E (2013) Spatiotemporal control of endocytosis by phosphatidylinositol-3, 4-bisphosphate. Nature 499 (7457):233-237

Posor Y, Eichhorn-Grünig M, Haucke V (2015) Phosphoinositides in endocytosis Molecular and cell biology of lipids.

Rigal A, Doyle SM, Robert S (2015) Live cell imaging of FM4-64, a tool for tracing the endocytic pathways in Arabidopsis root cells. Methods in molecular biology 1242:93-103. doi:10.1007/978-1-4939-1902-4_9

Rivas MP, Kearns BG, Xie Z, Guo S, Sekar MC, Hosaka K, Kagiwada S, York JD, Bankaitis VA (1999) Pleiotropic alterations in lipid metabolism in yeast sac1 mutants: relationship to "bypass Sec14p" and inositol auxotrophy. Molecular biology of the cell 10 (7):22352250. doi:10.1091/mbc.10.7.2235

Rodriguez-Furlan C, Minina EA, Hicks GR (2019) Remove, recycle, degrade: regulating plasma membrane protein accumulation. The Plant cell 31 (12):2833-2854 
952

953

954

955

956

957

958

959

960

961

962

963

964

965

966

967

968

969

970

971

972

973

974

975

976

977

978

979

980

981

982

983

984

985

986

987

Rodriguez-Villalon A, Gujas B, van Wijk R, Munnik T, Hardtke CS (2015) Primary root protophloem differentiation requires balanced phosphatidylinositol-4,5-biphosphate levels and systemically affects root branching. Development 142 (8):1437-1446. doi:10.1242/dev.118364

Roy A, Levine TP (2004) Multiple pools of phosphatidylinositol 4-phosphate detected using the pleckstrin homology domain of Osh2p. The Journal of biological chemistry 279 (43):44683-44689. doi:10.1074/jbc.M401583200

Schmid SL, Mettlen M (2013) Cell biology: Lipid switches and traffic control. Nature 499 (7457):161-162

Shin H-W, Hayashi M, Christoforidis S, Lacas-Gervais S, Hoepfner S, Wenk MR, Modregger J, Uttenweiler-Joseph S, Wilm M, Nystuen A (2005) An enzymatic cascade of Rab5 effectors regulates phosphoinositide turnover in the endocytic pathway. The Journal of cell biology $170(4): 607-618$

Simon ML, Platre MP, Assil S, van Wijk R, Chen WY, Chory J, Dreux M, Munnik T, Jaillais Y (2014) A multi-colour/multi-affinity marker set to visualize phosphoinositide dynamics in Arabidopsis. The Plant journal : for cell and molecular biology 77 (2):322-337. doi:10.1111/tpj.12358

Simon ML, Platre MP, Marques-Bueno MM, Armengot L, Stanislas T, Bayle V, Caillaud MC, Jaillais Y (2016) A Ptdlns(4)P-driven electrostatic field controls cell membrane identity and signalling in plants. Nat Plants 2:16089. doi:10.1038/nplants.2016.89

Song L, Wang Y, Guo Z, Lam SM, Shui G, Cheng Y (2021) NCP2/RHD4/SAC7, SAC6 and SAC8 phosphoinositide phosphatases are required for Ptdlns4P and Ptdlns $(4,5)$ P2 homeostasis and Arabidopsis development. New Phytologist

Takagi J, Uemura T (2018) Use of Brefeldin A and Wortmannin to Dissect Post-Golgi Organelles Related to Vacuolar Transport in Arabidopsis thaliana. Methods in molecular biology 1789:155-165. doi:10.1007/978-1-4939-7856-4_12

Tejos R, Sauer M, Vanneste S, Palacios-Gomez M, Li H, Heilmann M, van Wijk R, Vermeer JE, Heilmann I, Munnik T, Friml J (2014) Bipolar Plasma Membrane Distribution of Phosphoinositides and Their Requirement for Auxin-Mediated Cell Polarity and Patterning in Arabidopsis. The Plant cell 26 (5):2114-2128. doi:10.1105/tpc. 114.126185

Terebiznik MR, Vieira OV, Marcus SL, Slade A, Yip CM, Trimble WS, Meyer T, Finlay BB, Grinstein S (2002) Elimination of host cell Ptdlns $(4,5) P(2)$ by bacterial SigD promotes membrane fission during invasion by Salmonella. Nature cell biology 4 (10):766-773. doi:10.1038/ncb854

Thole JM, Vermeer JE, Zhang Y, Gadella TW, Jr., Nielsen E (2008) Root hair defective4 encodes a phosphatidylinositol-4-phosphate phosphatase required for proper root hair development in Arabidopsis thaliana. The Plant cell 20 (2):381-395. doi:10.1105/tpc.107.054304

van Leeuwen W, Vermeer JE, Gadella TW, Jr., Munnik T (2007) Visualization of phosphatidylinositol 4,5-bisphosphate in the plasma membrane of suspensioncultured tobacco BY-2 cells and whole Arabidopsis seedlings. The Plant journal : for cell and molecular biology 52 (6):1014-1026. doi:10.1111/j.1365-313X.2007.03292.x

Vollmer AH, Youssef NN, DeWald DB (2011) Unique cell wall abnormalities in the putative phosphoinositide phosphatase mutant AtSAC9. Planta 234 (5):993-1005. doi:10.1007/s00425-011-1454-4

Wickham $\mathrm{H}$ (2016) ggplot2: elegant graphics for data analysis. springer,

Williams ME, Torabinejad J, Cohick E, Parker K, Drake EJ, Thompson JE, Hortter M, Dewald DB (2005) Mutations in the Arabidopsis phosphoinositide phosphatase gene SAC9 lead to overaccumulation of Ptdlns(4,5)P2 and constitutive expression of the stressresponse pathway. Plant physiology 138 (2):686-700. doi:10.1104/pp.105.061317

Yan X, Wang Y, Xu M, Dahhan DA, Liu C, Zhang Y, Lin J, Bednarek SY, Pan J (2021) CrossTalk between Clathrin-Dependent Post-Golgi Trafficking and Clathrin-Mediated Endocytosis in Arabidopsis Root Cells. The Plant cell 
Yoshida S, Ohya Y, Goebl M, Nakano A, Anraku Y (1994) A novel gene, STT4, encodes a phosphatidylinositol 4-kinase in the PKC1 protein kinase pathway of Saccharomyces cerevisiae. The Journal of biological chemistry 269 (2):1166-1172 Yperman K, Papageorgiou AC, Merceron R, De Munck S, Bloch Y, Eeckhout D, Jiang Q, Tack
P, Grigoryan R, Evangelidis T (2021a) Distinct EH domains of the endocytic TPLATE complex confer lipid and protein binding. Nature communications 12 (1):1-11

Yperman K, Wang J, Eeckhout D, Winkler J, Dai Vu L, Vandorpe M, Grones P, Mylle E, Kraus M, Merceron R (2021b) Molecular architecture of the endocytic TPLATE complex. Science Advances 7 (9):eabe7999

Zhang Y, Persson S, Hirst J, Robinson MS, van Damme D, Sanchez-Rodriguez C (2015) Change your TPLATE, change your fate: plant CME and beyond. Trends in plant science 20 (1):41-48. doi:10.1016/j.tplants.2014.09.002

Zhao Y, Yan A, Feijo JA, Furutani M, Takenawa T, Hwang I, Fu Y, Yang Z (2010) Phosphoinositides regulate clathrin-dependent endocytosis at the tip of pollen tubes in Arabidopsis and tobacco. The Plant cell 22 (12):4031-4044. doi:10.1105/tpc. 110.076760

Zhong R, Burk DH, Morrison WH, 3rd, Ye ZH (2004) FRAGILE FIBER3, an Arabidopsis gene encoding a type II inositol polyphosphate 5-phosphatase, is required for secondary wall synthesis and actin organization in fiber cells. The Plant cell 16 (12):3242-3259. doi:10.1105/tpc.104.027466

Zhong R, Burk DH, Nairn CJ, Wood-Jones A, Morrison WH, 3rd, Ye ZH (2005) Mutation of SAC1, an Arabidopsis SAC domain phosphoinositide phosphatase, causes alterations in cell morphogenesis, cell wall synthesis, and actin organization. The Plant cell 17 (5):1449-1466. doi:10.1105/tpc.105.031377

Zhong R, Ye ZH (2003) The SAC domain-containing protein gene family in Arabidopsis. Plant physiology 132 (2):544-555. doi:10.1104/pp.103.021444

Zhuang X, Wang H, Lam SK, Gao C, Wang X, Cai Y, Jiang L (2013) A BAR-domain protein SH3P2, which binds to phosphatidylinositol 3-phosphate and ATG8, regulates autophagosome formation in Arabidopsis. The Plant cell 25 (11):4596-4615. doi:10.1105/tpc. 113.118307 